\title{
Epigenetik: \\ Einfluss auf die fetale Entwicklung
}

Bettina Brune, Thomas Brune

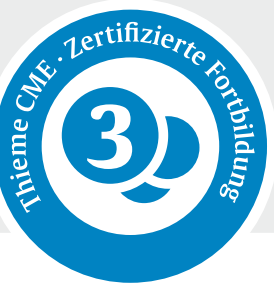

\begin{abstract}
„Der Mensch ist mehr als die Summe seiner Gene“. Wurde dieser Satz im Jahr 2002 kurz vor Abschluss des Humanen Genomprojekts (HGP) noch unter ethischen und moralphilosophischen Gesichtspunkten diskutiert, wurde danach schnell klar, dass er auch eine tiefergreifende wissenschaftliche Bedeutung für die gesamte Biologie hat als vorher angenommen.
\end{abstract}

\section{Einleitung}

Nach der offiziellen vollständigen Entschlüsselung des menschlichen Genoms im Jahr 2003 trat schnell eine deutliche Ernüchterung über die Bedeutung des Projekts ein. Waren zum Beginn noch mindestens 100000 Gene erwartet worden, um alle Merkmale des menschlichen Körpers kodieren zu können, stellte sich heraus, dass das Genom des Menschen lediglich aus rund 20000 - 30000 Genen besteht. Auf weit über $90 \%$ der DNA sind keine Gene, die für Proteine kodieren, lokalisiert.

Anstatt die These vom genetischen Determinismus zu bestätigen, machten die Ergebnisse des HGP klar, dass man bei nur wenigen Mutationen direkte Auswirkungen auf den Phänotyp des jeweiligen Lebewesens beobachten kann. Es wurde vielmehr offensichtlich, dass es nur in seltenen Fällen eine kausal gerichtete Beziehung zwischen Genotyp und Phänotyp gibt, sondern dass es sich bei der Ausprägung phänotypischer Merkmale um einen hochkomplexen Prozess von Wechselwirkungen und Rückkoppelungen zwischen DNA, RNA und Proteinen handelt.

Die dabei auftretenden Mechanismen sind durch Umweltfaktoren beeinflussbar und werden dem relativ jungen Fachgebiet der Epigenetik zugeordnet. Die im Laufe des Lebens entstehenden epigenetischen Veränderungen werden in Zusammenhang gebracht mit dem Auftreten von gesundheitlichen Beeinträchtigungen. Hierzu zählen chronische Erkrankungen wie zum Beispiel Diabetes mellitus Typ 2, koronare Herzkrankheit, Morbus Alzheimer, Depressionen sowie Tumorerkrankungen.
Insbesondere direkt nach der Befruchtung und während der Embryonal-, Fetal- und Neonatalphase reagiert der sich entwickelnde Organismus besonders vulnerabel. In dieser frühen Phase können durch Umwelteinflüsse induzierte epigenetische Veränderungen erhebliche Auswirkungen auf das gesamte Leben des Kindes haben.

\section{Grundlagen der Epigenetik}

\section{DEFINITION EPIGENETIK}

Der Begriff „Epigenetik“ wird für die Beschreibung von Vorgängen verwendet, die (teilweise auch vererbbare) Veränderungen der Aktivität von Genen bei gleichzeitig unveränderter DNASequenz hervorrufen. Die Epigenetik gilt als das Bindeglied zwischen den Genen und Umwelteinflüssen.

Geprägt wurde der Begriff Epigenetik bereits Mitte des 20. Jahrhunderts durch den Evolutionsforscher Conrad Waddington, dieser beschrieb damit eine stetige Wechselbeziehung zwischen Genen und Umwelt, durch die der Phänotyp eines Individuums beeinflusst werden kann [1].

\section{Merke}

Die Epigenetik wird als Schnittstelle zwischen Genetik und Umwelt verstanden.

Alle 100 Billionen Zellen, aus denen der menschliche Organismus aufgebaut ist, enthalten die gleiche genetische Erbinformation in der DNA verschlüsselt. Um ihren jeweiligen Aufgaben im Körper gerecht zu werden, spezialisieren sich die Zellen im Laufe ihrer Entwicklung und man unterscheidet mehr als 200 verschiedene Zelltypen ( $\triangleright$ Abb. 1). Möglich ist dies, da in den Zellen nicht 


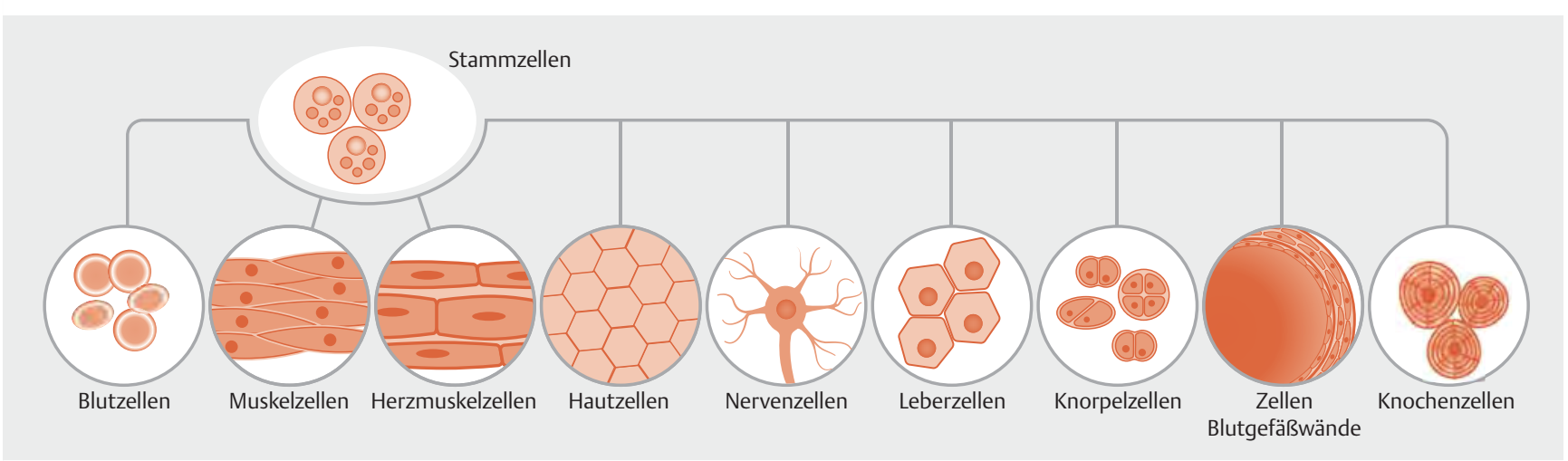

Abb. 1 Zellspezialisierung.

alle Gene gleichzeitig abgelesen, sondern je nach Funktion bzw. Bedarf der jeweiligen Zelle ein- oder ausgeschaltet bzw. stärker oder schwächer exprimiert werden.

\section{Merke}

Alle Zellen im Organismus enthalten die gleiche Erbinformation, aber nicht alle Gene werden in jeder Zelle exprimiert.

Die Regulation der Genexpression wird über verschiedene epigenetische Mechanismen vermittelt. Neben der DNA-Methylierung zählen hierzu auch die Modifikationen von Chromatin, z.B. durch Histonmethylierung, -acetylierung oder -phosphorylierung, sowie die Wechselwirkungen von microRNA mit der DNA.

EPIGENETISCHE MECHANISMEN DER GENREGULATION

- DNA-Methylierung

- Modifikation von Histonen

- RNA-Interferenz

\section{METHYLGRUPPENÜBERTRAGUNG IN DER ZELLE}

Substanzen, die im Stoffwechsel Methylgruppen abgeben oder übertragen, werden als Methyldonatoren bzw.- akzeptoren bezeichnet. Dazu zählen auch die mit der Nahrung zugeführten Nährstoffe Folate (synthetische Form: Folsäure), Methionin, Cholin und Betain. Darüber hinaus sind die Vitamine $B_{2}$, $B_{6}$ und $B_{12}$ an der enzymatischen Übertragung der Methylgruppen im Stoffwechsel beteiligt.
Die Kombination aller epigenetischen Merkmale einer Zelle kann man als ihren epigenetischen Code bezeichnen. Durch ihn sind die Zellen in der Lage, trotz gleicher genetischer Ausstattung auch hochspezialisierte Funktionen zu übernehmen, z. B. als Herz-, Leber- oder Nervenzelle. Das etablierte unterschiedliche epigenetische Muster der Zelle wird bei der mitotischen oder meiotischen Zellteilung an die jeweiligen Tochterzellen weitergegeben.

\section{Merke}

Die Genexpression in der Zelle wird über verschiedene epigenetische Mechanismen reguliert.

\section{DNA-Methylierung}

Die Markierung der DNA durch Methylgruppenanheftung an bestimmten Stellen dient als Schalter, der Gene aktivieren oder stilllegen kann. Sie besitzt damit eine weitreichende Bedeutung für die Genregulation bei Säugetieren und Menschen.

Bei diesem Vorgang wird eine Methylgruppe des SAdenosylmethionin (SAM) durch DNA-Methyltransferasen (DNMT) enzymatisch auf die DNA-Base Cytosin übertragen. Dies geschieht mittels kovalenter Bindung an der 5. Position des Pyrimidinrings, dabei entsteht 5Methyl-Cytosin ( $>$ Abb. 2).

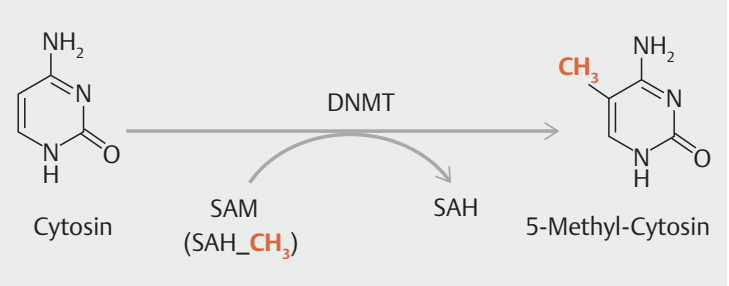

Abb. 2 Übertragung der reaktiven Methylgruppe von SAdenosylmethionin (SAM) durch DNA-Methyltransferasen (DNMT) auf Cytosin. Es entstehen 5-Methyl-Cytosin und SAdenosylhomozystein (SAH). 
Übertragung von Methylgruppen in der Zelle Im Prinzip können in der Zelle 2 verschiedene Systeme des Methylgruppentransfers unterschieden werden, die in der Zelle parallel ablaufen und die über eine gemeinsame Schnittstelle, das Vitamin $B_{12}$, miteinander verbunden sind:

- DNA-Zyklus

- Methylierungszyklus

DNA-Zyklus

Die mit der Nahrung aufgenommenen, überwiegend nicht methylierten Folate werden zunächst in der Leber in 5-Methyl-Tetrahydrofolsäure (5-Methyl-THF) umgewandelt. Nach Aufnahme des 5-Methyl-THF in die Zelle wird im ersten Schritt die Methylgruppe an das als Koenzym dienende Vitamin $B_{12}$ abgegeben. Es entsteht Tetrahydrofolsäure (THF), die als Ausgangsprodukt für den DNA-Zyklus zur Verfügung steht. Dieses wird zunächst in 5,10-Methylen-Tetrahydrofolsäure (5,10-Methylen-THF) umgewandelt. Die hierfür benötigten Hydroxymethylgruppen werden an dieser Stelle durch die Umwandlung von Serin in Glycin in Anwesenheit des Enzyms Serin-Hydroxymethyl-Transferase aus dem Aminosäurestoffwechsel geliefert.

Im nächsten Schritt kann dann zum einen die Pyrimidinsynthese erfolgen, bei der Dihydrofolat (DHF) entsteht, das durch die DHF-Reduktase wieder zu THF umgewandelt wird. Zum anderen kann 5,10-Methylen-THF auch für die Purinsynthese verwendet werden, dafür wird es zuvor in einer Zwischenreaktion zu 10-Formyl-THF umgewandelt. Schließlich wird auch bei diesem Stoffwechselschritt erneut THF gebildet. Pyrimidine und Purine werden für die DNA-Synthese verwendet. Als dritte Möglichkeit kann 5,10-Methylen-THF darüber hinaus in einer irreversiblen Reaktion zu 5-Methyl-THF umgewandelt werden.

Im Gegensatz zu natürlichem Nahrungsfolat gelangt synthetisch hergestellte Folsäure als Vorstufe des THF ohne den Umweg über 5-Methyl-THF in den zellulären DANN-Zyklus; sie wird durch das Enzym DihydrofolatReduktase in einem ersten Zwischenschritt zu Dihydrofolat und dann zu THF umgewandelt.

\section{Methylierungszyklus}

Die vom Vitamin $B_{12}$ übernommene Methylgruppe des 5-Methyl-THF wird in den Methylierungszyklus eingeschleust und mithilfe des Enzyms Methionin-Synthase auf die Aminosäure Homocystein übertragen. Es entsteht die Aminosäure Methionin, die beim Abbau durch die Übertragung des aktivierten Adenosylrests eines ATP-Moleküls in S-Adenosylmethionin (SAM) umgewandelt wird. SAM steht als Methyldonor für zahlreiche Reaktionen zur Verfügung, wie z.B. die Methylierung von Proteinen, Phospholipiden, DNA und RNA.

\begin{abstract}
Merke
S-Adenosylmethionin (SAM) ist als Substrat an zahlreichen Transmethylierungen im Stoffwechsel beteiligt und spielt bei der DNA-Methylierung durch DNAMethyltransferasen eine wichtige Rolle.
\end{abstract}

Für den reibungslosen Ablauf des Methylierungszyklus sind Folate bzw. Folsäure in Form von 5-Methyl-THF und $B_{12}$ notwendig. Ein Mangel führt zu einem Defizit an SAM und einem Anstieg des Homozysteins. Eine inadäquate Versorgung kann kompensatorisch durch die Bildung von Methionin mithilfe von Cholin bzw. Betain ausgeglichen werden. Abb. $\mathbf{3}$ zeigt einen einfachen schematischen Überblick über die Abläufe der beiden Zyklen in der Zelle, die jeweiligen wichtigsten Zielfunktionen im Stoffwechsel und den Transfer der Methylgruppen.

\section{Merke}

Für einen reibungslosen Ablauf des Methylierungszyklus in der Zelle ist eine ausreichende Verfügbarkeit der beteiligten Nährstoffe Folat/Folsäure, $B_{2}, B_{6}, B_{12}$ und Methionin (alternativ Betain) notwendig.

Der DNA-Doppelstrang enthält:

- Adenin

- Thymin

- Guanin

- Cytosin

Diese 4 Basen bilden die Sprossen der Leiter und sind jeweils fest mit den Zuckermolekülen verknüpft, die sich mit Phophatgruppen abwechseln und wie bei einer Strickleiter die Stränge bilden. Die beiden miteinander locker über Wasserstoffbrücken verbundenen Stränge sind einander komplementär aufgebaut-Adenin ist immer mit Thymin, Guanin immer mit Cytosin gepaart.

Von den 4 DNA-Basen (Adenin, Thymin, Guanin und Cytosin) wird nur das Cytosin methyliert.

Die Methylierung des Cytosins findet bei Wirbeltieren hauptsächlich innerhalb von Cytosin-Phosphat-Guanin-Dinukleotiden (CpG-Dinukleotiden) auf beiden komplementären DNA-Strängen statt und führt zu einer veränderten 3-dimensionalen Struktur der DNA ( $\triangleright$ Abb. 4). Der Buchstabe „P“ in CpG bezeichnet die Phosphodiesterbindung zwischen den Nukleosiden Cytidin und Guanosin und wird angegeben, um zwischen dem hier erwähnten CG innerhalb eines DNA-Strangs und der CG-Basenpaarung eines DNA-Duplexes zu unterscheiden.

Merke

Die Methylierung des Cytosins findet hauptsächlich innerhalb von CpG-Dinukleotiden statt. 


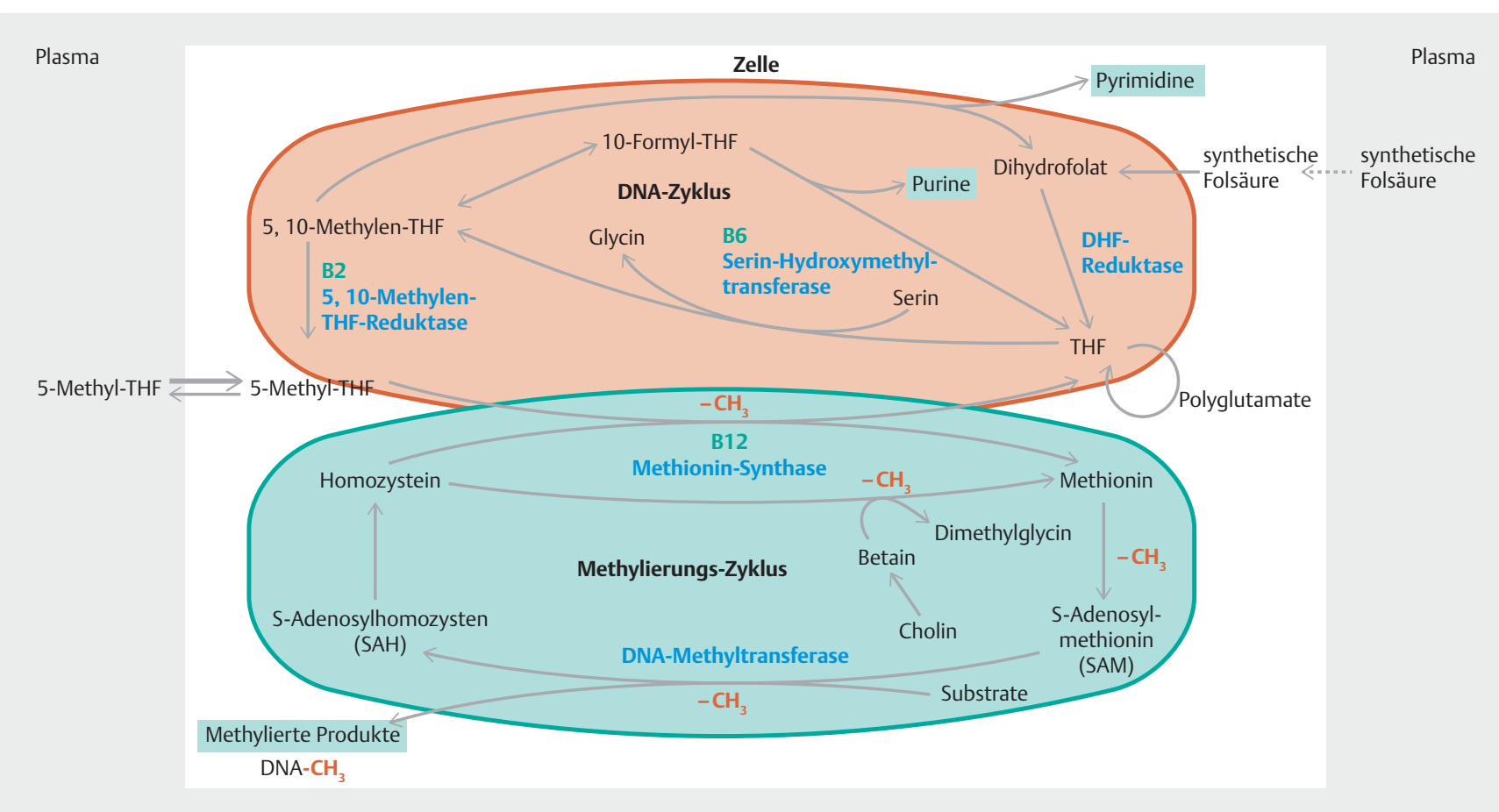

Abb. 3 Schematische Darstellung des Methylierungszyklus (modifiziert nach: FAO/WHO. FAO/WHO Expert Consultation on human vitamin and mineral requirements: Folate and folic acid. Rom: FAO; 2001: 53-62) [2].

CpG-Dinukleotide (CpG-Ort, englisch: CpG-site) kommen im gesamten Genom nur in sehr geringer Menge vor $(<1 \%)$; in bestimmten Abschnitten der DNA konzentrieren sie sich jedoch in statistisch erhöhter Dichte. Solche Regionen werden als CpG-Inseln (engl. CpG-sites) bezeichnet; sie kommen gehäuft in der Promotorregion eines Gens vor, die in der Regel vor dem Gen lokalisiert ist [2]. Der Promotor tritt in Wechselwirkung mit bestimmten DNA-bindenden Proteinen, die den Start der Transkription des Gens durch das Enzym RNA-Polymerase vermitteln und als Transkriptionsfaktoren bezeichnet werden.

Während die CpG-Inseln im Gesamtgenom überwiegend methyliert vorliegen, trifft dies für diejenigen im Promotorbereich von Genen meist nicht zu. Im nicht methylierten Zustand ermöglichen sie als potenzielle Bindungsstellen für Methylgruppen die Regulation der Genexpression durch die Beeinflussung der Transkriptionsvorgänge. Ihre Methylierung durch Anlagerung einer Methylgruppe und die dadurch bedingte Strukturveränderung der DNA in diesem Genabschnitt hat zur Folge, dass die Transkriptionsfaktoren nicht binden können und das Gen infolgedessen nicht abgelesen werden kann: Es wird stillgelegt ( $\triangleright$ Abb. 5).

In der Regel wird daher die Genexpression durch Methylierung unterdrückt. Im umgekehrten Fall bewirkt eine Demethylierung in der Promotorregion, dass ein stillgelegtes Gen reaktiviert wird und die kodierte Information abgelesen und übertragen werden kann.

\section{Merke \\ Die Methylierung in der Promotorregion eines Gens führt in der Regel zu seiner verminderten Expression oder sogar Inaktivierung.}

\section{Modifikation von Histonen}

In jeder Zelle befinden sich nahezu 2 Meter DNA. Der weitaus größte Anteil ist im Nukleus von nur einigen $\mu \mathrm{m}$ Durchmesser lokalisiert, sehr wenig DNA befindet sich auch außerhalb des Zellkerns in den Mitochondrien. Um im Nukleus Platz zu finden, ist eine enorme Verkleinerung der DNA-Stränge notwendig. Hierzu ist die DNA um spezielle kugelige Histonproteine spulenartig aufgewickelt, mit jeweils 8 von ihnen zusammen bildet sie die Nukleosomen, die kettenförmig aneinandergereiht sind. Zusammen mit weiteren Nichthistonproteinen lagern sie sich zu einer noch kompakteren Struktur zusammen und werden als Chromatin(fäden) bezeichnet. Nur während der Zellteilung wickeln sich diese 46 Fäden ähnliche wie Wollfäden zu den dann sichtbar werdenden Chromosomen auf ( $\triangleright$ Abb. 6). 


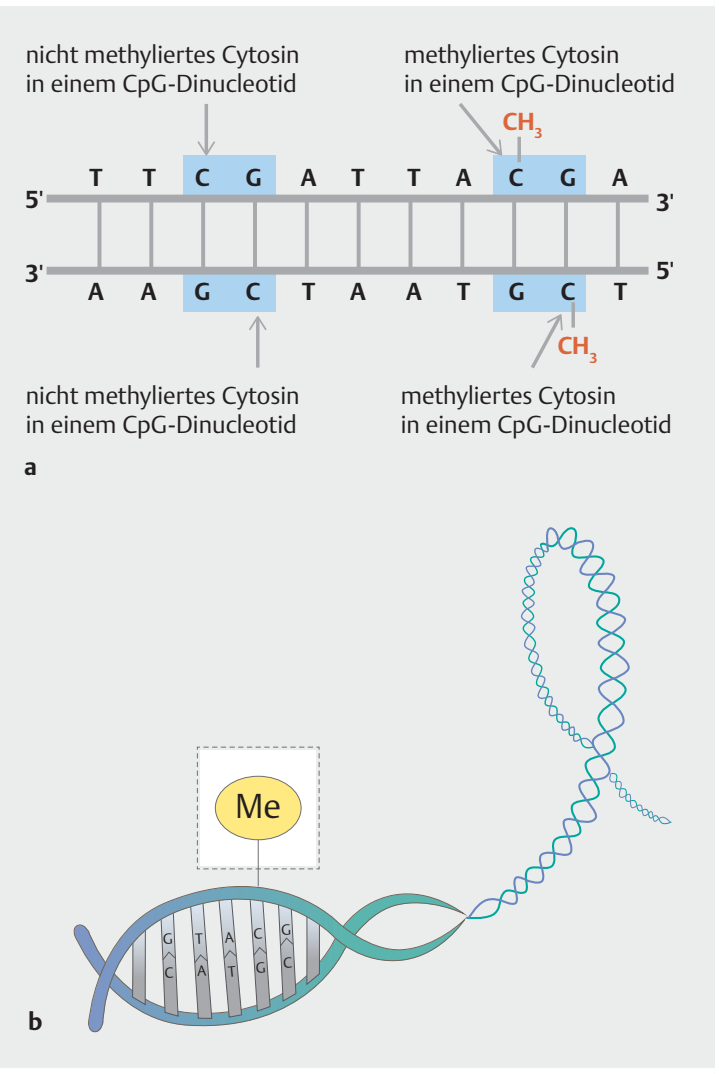

Abb. 4 a Übertragung von Methylgruppen auf die DNAMethylierung innerhalb von Cytosin-Phosphat-Guanin-Dinukleotiden (CpG-Dinukleotiden). b Veränderung der 3dimensionalen Struktur der DNA durch Anlagerung von Methylgruppen an Cytosinbasen (modifiziert nach: Kwapiszewska G, Viales R, Ehlken N et al. Epigenetik und Genetik der pulmonal arteriellen Hypertonie - neue Erkenntnisse der letzten Jahre. DMW 2014; 139: 111 -115).

Merke

Die DNA-Stränge sind im Zellkern spulenartig auf kugelige Histonproteine aufgewickelt, die mit weiteren Proteinen eng zusammengelagert sind. Gemeinsam mit der DNA bilden sie die veränderbare Chromatinstruktur.

Es ist notwendig, dass die Gene trotz der dichten Zusammenlagerung der DNA abgelesen und transkribiert, d. h. exprimiert werden können, so dass die Synthese von RNA und schließlich der Proteine stattfinden kann. Dies wird ermöglicht, in dem der Verpackungsgrad der Nukleosomen je nach Bedarf verändert werden kann - eine dichte Verpackung macht die Gene unzugänglich für Moleküle und Enzyme, eine Lockerung dagegen aktiviert die betroffenen Abschnitte und ermöglicht eine Genaktivierung.

Beeinflusst werden kann der Verpackungsgrad durch die Anlagerung verschiedener Moleküle an den Enden der Histone, die wie Antennen herausragen. Von den 4 verschiedenen Histonarten ( $\mathrm{H} 2 \mathrm{~A}, \mathrm{H} 2 \mathrm{~B}, \mathrm{H} 3$ und $\mathrm{H} 4)$ be-
Genexpression bei demethylierten CpG-Islands in der Promoterregion

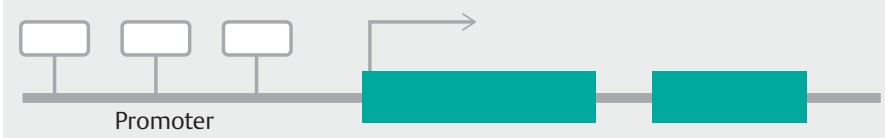

Gene-Silencing (Gen Stilllegung) durch DNA-Methylierung

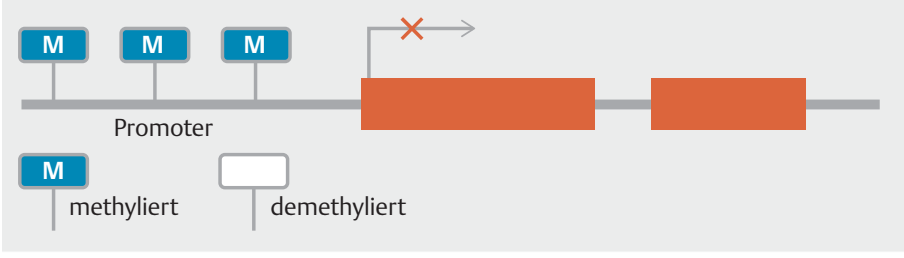

- Abb. 5 Steuerung der Genaktivitat durch Methylierung (modifiziert nach: Mau T, Yung R. Potential of epigenetic therapies in non-cancerous conditions. Front Genet 2014;5:438).

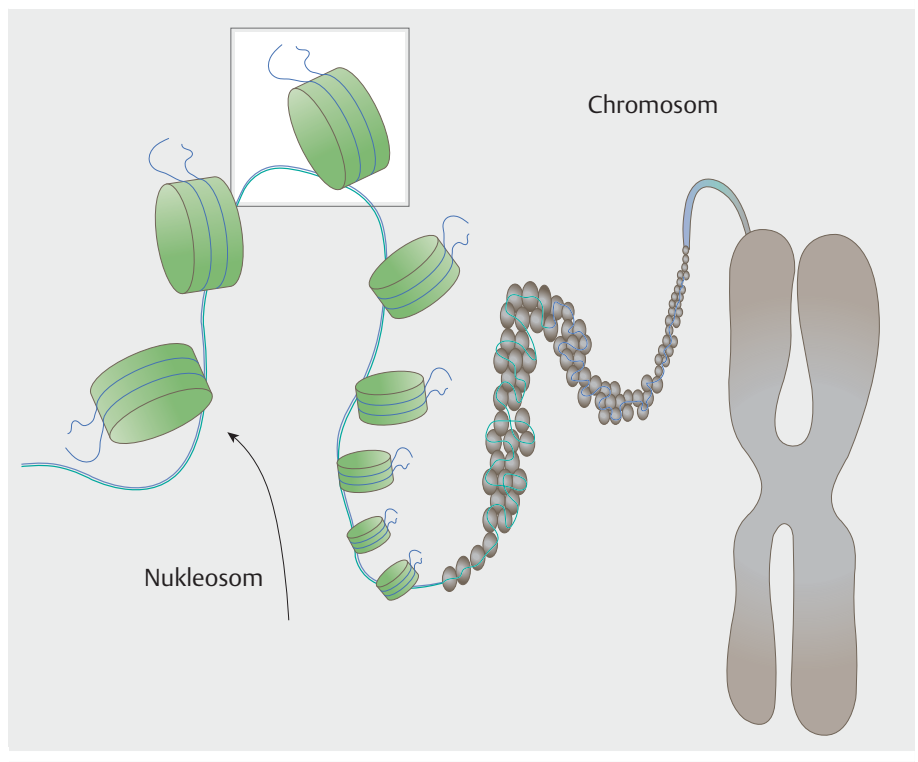

Abb. 6 Spulenartige Aufwicklung der DNA auf Histone (aus: Kwapiszewska G, Viales R, Ehlken N et al. Epigenetik und Genetik der pulmonal arteriellen Hypertonie - neue Erkenntnisse der letzten Jahre. DMW 2014; 139: 111 -115).

sitzen die Histone $\mathrm{H} 3$ und $\mathrm{H} 4$ besonders lange Schwänze, an denen Enzyme gezielt chemische Strukturen anlagern können. Neben der Acetylierung, Methylierung, Phosporylierung oder Ubiquitinierung gibt es zahlreiche weitere Möglichkeiten, Histone zu modifizieren. Das Andocken von Acetylgruppen kann darüber hinaus auch wiederum das Anbinden von Eiweißen ermöglichen, die die Genregulation direkt beeinflussen. In diesem Zusammenhang wird der Begriff „Histon-Code“ im Erbgut einer Zelle diskutiert. Je nachdem, welches Molekül und Protein an welchen Ort eines Histonschwanzes bindet, verändert sich die räumliche Struktur der Histone und der umgebende DNA-Faden wird für Interaktionen mit Transkriptionsfaktoren zugänglicher. Die dadurch induzierte Veränderung der Chromatinstruktur ermöglicht somit die Aktivierung einzelner Gene 
oder auch ganzer DNA-Abschnitte mit mehreren Genen. Im Gegensatz dazu kann bei der Verdichtung des Chromatins zu Heterochromatin an dieser Stelle kein Gen mehr abgelesen werden, sondern wird stumm geschaltet.

\section{Merke}

Durch die Lockerung der Chromatinstruktur durch Histonmodifikation werden DNA-Abschnitte für Transkriptionsfaktoren zugänglich gemacht.

\section{Nicht kodierende RNA}

Erstaunlicherweise sind auf weit über $90 \%$ der DNA keine Gene lokalisiert, die für Proteine kodieren, diese Abschnitte wurden lange Zeit für überflüssige „Junk“-DNA gehalten. Mittlerweile ist bekannt, dass sie den Code für sog. nicht kodierende RNA enthalten. Diese verschieden langen Moleküle sind in der Lage, die Aktivität spezifischer Gene zu verringern oder sie sogar ganz abzuschalten.

Ein Beispiel für ein sehr langes Transkript stellt die XistRNA (X inactive specific transcript) dar, die eine entscheidende Rolle bei der Inaktivierung eines der beiden X-Chromosomen im weiblichen Embryo spielt.

Sehr kurze RNA-Moleküle, sog. microRNAs, sind in der Lage, posttranskriptional gezielt die Übersetzung eines Gens in ein Protein durch das Abfangen und Zerstören der hierzu benötigten mRNA zu hemmen; sie übernehmen damit eine bedeutende Funktion als Regulatoren der Translation. Dieser Vorgang wird auch als RNA-Interferenz bezeichnet ( $\triangleright$ Abb. 7). Die Funktionen der meisten ca. 1000 bekannten microRNAs sind noch nicht bekannt.

\section{Merke}

Beim Vorgang der RNA-Interferenz können microRNAs posttranskriptional gezielt die Übersetzung eines Gens in ein Protein hemmen.

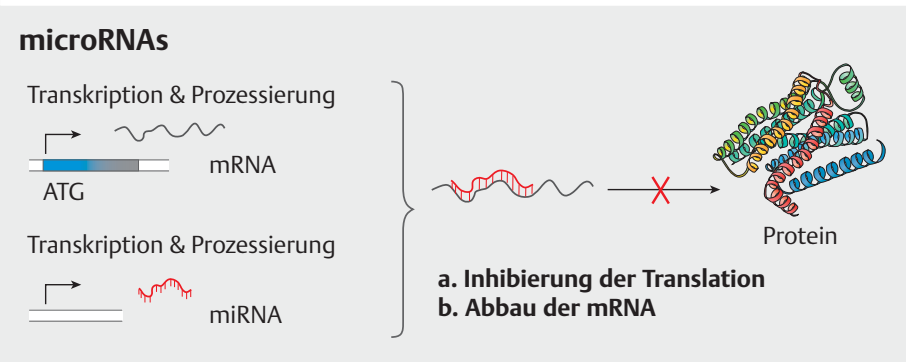

Abb.7 Regulation der Translation durch micoRNAs. (aus: Kwapiszewska G, Viales R, Ehlken $\mathrm{N}$ et al. Epigenetik und Genetik der pulmonal arteriellen Hypertonie - neue Erkenntnisse der letzten Jahre. DMW 2014; 139: $111-115)$.

\section{Zusammenfassung: Epigenetische Genregulation}

Die epigenetische Genregulation kann als Zusammenspiel der verschiedenen Mechanismen betrachtet werden; durch Interaktionen können in einer Zelle gezielt epigenetische Muster erstellt und variiert werden. Die zugrunde liegenden Abläufe sind äußerst komplex und in ihren gegenseitigen Wechselspielen noch nicht vollständig verstanden.

Die Untersuchungen epigenetischer Vorgänge werden durch den Umstand erschwert, dass Einflüsse individuell unterschiedlich im Erbgut „verarbeitet“ werden. Sogar bei eineiigen Zwillingen wurde festgestellt, dass die Epigenome sich bereits zum Zeitpunkt der Geburt voneinander unterscheiden, wenn auch nicht so stark wie bei zweieiigen Zwillingen [3].

\section{Merke}

Man wird daher immer nur eine Art „Schnappschuss“ eines kurzfristigen epigenetischen Zustands einer bestimmten Zelle eines Individuums zu einem bestimmten Zeitpunkt darstellen können.

Während die epigenetische Bedeutung der Histonmodifikation und der nicht kodierenden RNA im Organismus erst in den letzten Jahren zunehmend wahrgenommen wurde, ist die Methylierung der DNA der bisher am besten untersuchte epigenetische Mechanismus. In diesem Artikel wird der Schwerpunkt daher auf Vorgänge gelegt, die die globale oder genspezifische Methylierung der DNA betreffen.

\section{Epigenetische Veränderungen beim Feten}

Es ist bekannt, dass bestimmte Lebensphasen mit teils gravierenden Veränderungen der DNA-Methylierung einhergehen. Innerhalb dieser Zeitfenster ist der Organismus besonders störanfällig für Fehlentwicklungen, die sich kurz- oder langfristig auf die Gesundheit auswirken können.

Im besonderen Fokus stehen hier die Embryonalperiode, in der die Methylierungsmuster im Embryo - und separat auch in seinen Keimzellen, der übernächsten Generation - grundlegend etabliert werden, sowie die gesamte Fetalzeit, in der der Organismus heranreift und für zukünftige (Über-)Lebensanforderungen im Sinne einer Programmierung vorbereitet wird.

Darüber hinaus finden auch während der frühen Kindheit und der Pubertät wichtige Prozesse statt, die den Organismus längerfristig prägen können. Schließlich werden im Seniorenalter viele Beobachtungen gemacht, 
inwieweit sich bestimmte Erkrankungen manifestieren, die (ursächlich oder als Folge) im Zusammenhang mit einer veränderten DNA-Methylierung stehen.

\section{Merke}

Während bestimmter Zeitfenster im Leben ist der Organismus sehr vulnerabel gegenüber Störfaktoren. Besonders kritische Lebensphasen sind die Embryonal- und Fetalzeit, die frühe Kindheit und Pubertät sowie das Seniorenalter.

Der intrauterinen Wachstumsphase kommt eine ganz besondere Bedeutung zu, da der sich entwickelnde Organismus in dieser Zeit äußerst empfindlich auf seine Umgebung reagiert. Die epigenetischen Markierungen der DNA müssen zunächst im 1. Stadium des beginnenden neuen Lebens primär erstellt und stabilisiert werden. Dabei sind die sich etablierenden Zellsysteme, insbesondere die neuronalen, sehr anfällig für Störungen. Fehlerhafte Merkmale können dann an die Tochterzellen weitergegeben werden und zu gravierenden Krankheitsbildern führen. Es wird vermutet, dass eine fehlerhafte Ausbildung der DNA-Methylierungsmuster in einem sehr frühen Stadium der intrauterinen Entwicklung beispielsweise zur Entstehung von gravierenden Fehlbildungen des Neuralrohrs führen kann [4].

\section{Reprogrammierung der Methylierungs- muster im Embryo}

Gleich zu Beginn ihres Lebens gibt es bei Säugetieren 2 entscheidende Entwicklungsabschnitte, in denen das Epigenom durch Löschung und Neuetablierung der bis dahin bestehenden Methylierungsmuster einer tiefgreifenden Neuprogrammierung unterzogen wird [5]: Betroffen sind zum einen die befruchtete Eizelle noch vor ihrer Implantation in die Gebärmutter, zum anderen kurze Zeit später die embryonalen Urkeimzellen (synonym: primordiale Keimzellen), die die Vorläufer der Ei- bzw. Samenzellen sind.

\section{Zygote: Erste Reprogrammierung}

Die erste Demethylierung erfolgt, sobald Ei- und Samenzelle bei der Befruchtung verschmolzen sind und die Zygote entstanden ist. Zunächst werden die Methylierungsmuster auf dem väterlichen Allel gelöscht, kurze Zeit später auch die des mütterlichen. Nur bei einigen wenigen Genen, die dem Imprinting unterliegen, bleibt die Methylierung erhalten.

Diese erste nahezu vollständige Löschung der Programmierung ermöglicht die neue Ausbildung genspezifischer Methylierungsmuster, die schließlich zu gewebespezifischen Transkriptionsvorgängen führen. Sie ist notwendig für die Entwicklung des totipotenten Potenzials der embryonalen Stammzellen, da die beiden fusionierten Keimzellen jeweils sehr unterschiedliche Epigenome aufweisen.

\section{NEURALROHRDEFEKT}

Seit Beginn der 1960er Jahre wurde ein Zusammenhang zwischen einer in der Frühschwangerschaft nicht ausreichenden Versorgung mit dem in der Nahrung enthaltenen Vitamin Folat und dem Auftreten von Neuralrohrdefekten (NRD) vermutet. Ursächlich zugrunde liegt ein unvollständiger Verschluss des fetalen Neuralrohrs. Die entscheidende Zeitspanne für diese gravierende Entwicklungsstörung liegt innerhalb eines sehr kleinen Zeitfensters während der Frühschwangerschaft. Die Mechanismen, die zur Entstehung von Neuralrohrdefekten unterschiedlichen Ausmaßes führen, sind vielfältig und bislang noch nicht vollständig geklärt. Anfang der 1990er Jahre konnte die Reduzierung des Auftretens von Neuralrohrdefekten durch eine perikonzeptionelle Einnahme von Folsäure, der synthetisch hergestellten Form des Vitamins Folat, nachgewiesen werden.

\section{Merke}

Embryonale Stammzellen sind Vorläufer für alle Körperzellen einschließlich der Keimzellen. Im Verlauf ihrer Spezialisierung verlieren sie schrittweise ihre Totipotenz.

Aus der Zygote entwickelt sich schließlich die Blastozyste, und noch vor ihrer Einnistung in den Uterus erfolgt die De-novo-Remethylierung des Genoms. Während des Blastozystenstadiums findet bei weiblichen Embryonen (beim Menschen am 16. Tag nach der Befruchtung) die Inaktivierung eines der beiden X-Chromosomen statt, dabei spielt das bereits erwähnte XistGen eine wichtige Rolle.

\section{IMPRINTING}

Beim Imprinting, auch als „genomische Prägung“ bezeichnet, handelt es sich um einen Spezialfall der Genstillegung, bei dem gezielt entweder das maternale oder das paternale Allel durch DNA-Methylierung abgeschaltet wird. Die Genexpression hängt demnach davon ab, von welchem Elternteil das Allel stammt. Dieser epigenetische Vorgang der alternativen Stilllegung entweder des mütterlichen oder des väterlichen Allels beeinflusst damit den Phänotyp der Nachkommen, ohne den genetischen Code der Nukleotid-Basensequenz zu verändern. Die Genstillegung durch Imprinting zählt zu den wichtigsten Prozessen, die durch DNA-Methylierung gesteuert werden. 


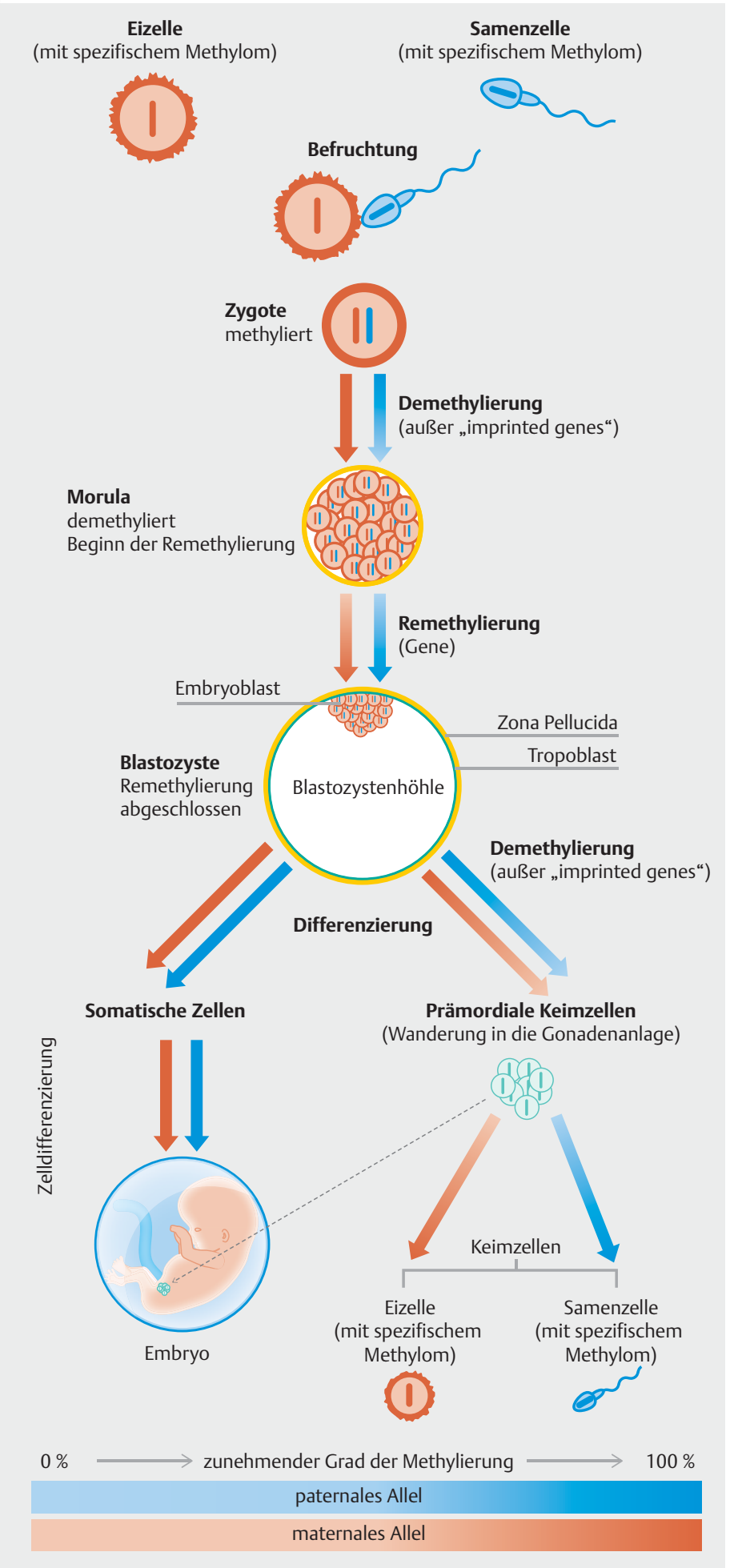

- Abb. 8 Reprogrammierungsdynamik der globalen DNA-Methylierung während des Lebenszyklus (mod. nach [5]).

\section{Merke}

Beim Menschen und vermutlich allen höheren Säugetieren ist es vom Zufall abhängig, welches der beiden vorhandenen X-Chromosomen während der Embryonalentwicklung in einer Zelle inaktiviert wird. Dies ist eine mögliche Ursache für die stärker ausgeprägten phänotypischen Unterschiede bei eineiigen weiblichen Zwillingen (aktives X entweder maternal oder paternal) gegenüber eineiigen männlichen Zwillingen (aktives $\mathrm{X}$ immer maternal).

\section{X-CHROMOSOMALE INAKTIVIERUNG}

Im weiblichen Embryo von Säugetieren wird eines der beiden X-Chromosomen stillgelegt durch die Ausbreitung der Xist-RNA, Hypoacetylierung der Histone sowie DNA-Methylierung. Bei diesem Vorgang wird die DNA so eng verpackt, dass die Gene auf dem betroffenen X-Chromosom nicht mehr abgelesen werden können. Entsprechend inaktivierte und verdichtete X-Chromosomen werden als „Barr-Körper“ bezeichnet.

\section{Gonaden: Zweite Reprogrammierung}

Ein 2. Mal wird das Methylierungsmuster in der frühen Embryonalphase in den Urkeimzellen während ihrer Wanderung in die Gonadenanlagen innerhalb kurzer Zeit gelöscht; diesmal sind auch Gene betroffen, die dem Imprinting unterliegen. Ein komplett neuer Methylierungsstatus der embryonalen Keimzellen ermöglicht beim weiblichen Embryo eine Aktivierung des stillgelegten X-Chromosoms, so dass in den heranreifenden Eizellen potenziell beide $X$-Chromosomen für die Entwicklung der nächsten Generation genutzt werden können. Auch fehlerhafte Epimutationen, die andernfalls immer an die Folgegenerationen weitergegeben würden, können auf diese Weise gelöscht werden. Während der weiteren Gonadenentwicklung werden dann geschlechtsspezifische Methylierungsmuster neu etabliert.

Die während der Embryogenese etablierten Methylierungsmuster bleiben im Wesentlichen in den Zellen erhalten und werden über mitotische und meiotische Zellteilung an alle neu entstehenden Tochterzellen weitergegeben. Die 2 Phasen der Reprogrammierung sind in $\mathbf{A b b} . \mathbf{8}$ dargestellt. 


\section{Beeinflussung der fetalen DNA-Methylierung durch Umweltfaktoren}

Lange wurde angenommen, dass die in einem frühen Stadium etablierte DNA-Methylierung sehr stabil ist und im Laufe des Lebens nicht oder nur in geringem Umfang auch durch externe Faktoren veränderbar ist. Mittlerweile zeigen Studien jedoch, dass es sich hierbei um eine temporäre Modifikation im Erbgut handelt, die im Sinne eines Anpassungsprozesses durch Umweltfaktoren beeinflusst werden kann, z. B. durch:

- Lebensstil

- Stress

- soziale Erfahrungen

- physikalische Faktoren

- chemische Substanzen

- bestimmte Nährstoffe

Forschungsergebnisse von Untersuchungen an eineiigen Zwillingen liefern Hinweise, dass bei gleicher Genausstattung das Erkrankungsrisiko z. B. für Brustkrebs, Insulinresistenz oder Diabetes im Laufe des Lebens durch unterschiedliche epigenetische Vorgänge beeinflusst wird [7]. Neu entstehende Hypo- oder auch Hypermethylierungen scheinen auch eine Rolle bei der Karzinogenese und der Entwicklung chronischer Erkrankungen zu spielen. Dabei können Veränderungen einerseits die globale Methylierung der DNA betreffen. Das bedeutet, dass der Gesamtanteil an methylierten Cytosinen in der DNA vermindert (= globale Hypomethylierung) oder erhöht (= globale Hypermethylierung) ist. Auf der anderen Seite können auch gezielt bestimmte Gene hypo- bzw. hypermethyliert und damit aktiviert bzw. stillgelegt werden.

Merke

Eineiige Zwillinge haben im Laufe ihres Lebens trotz gleicher Erbanlagen ein unterschiedliches Risiko, chronische Erkrankungen zu entwickeln.

Es gibt nicht wenige Einflussfaktoren während der Schwangerschaft, die plazentar bzw. über die mütterliche Umgebung vermittelt werden und bei denen vermutet wird, dass sie zu fehlerhaften epigenetischen Markierungen beim sich entwickelnden Ungeborenen führen (s. Infobox).

Merke

Beim Feten können epigenetische Markierungen durch (Dys-)Stress, bestimmte chemische Substanzen, Rauchen, maternale Stoffwechselsituation und Nährstoffaufnahme während der Schwangerschaft verändert werden.
IMPRINTING-STÖRUNGEN

Störungen des biologisch hochsensiblen Vorgangs der embryonalen Reprogrammierung können gravierende Auswirkungen haben. Beispiele für Imprinting-Erkrankungen aufgrund fehlerhafter genomischer Prägung sind:

- Prader-Willi-Syndrom (PWS)

- Angelman-Syndrom (AS)

- Beckwith-Wiedemann-Syndrom (BWS)

- Silver-Russel-Syndrom (SRS)

- transienter neonataler Diabetes mellitus (TNDM)

- upd(14)-Syndrome

Ursächlich liegen Fehler bei der Löschung, Etablierung oder Erhaltung des genomischen Imprintings zugrunde, die durch (epi-)genetische Mechanismen zu einem Funktionsverlust des einen aktiven Allels oder die Verdopplung seiner Dosis führen können. Die klinische Verdachtsdiagnose kann häufig durch einen DNA-Methylierungstest bestätigt werden.

Es gibt Hinweise, dass bei künstlicher Befruchtung (englisch: assisted reproductive technologies, ART) das kindliche Risiko für die insgesamt sehr selten auftretenden Imprinting-Erkrankungen erhöht wird. Bei BWS-Patienten wurde eine höhere Rate an betroffenen Neugeborenen nach künstlicher Befruchtung beobachtet [6]. Die Ursachen hierfür sind noch nicht geklärt. Ein externer Einflussfaktor könnte in dieser Hinsicht das Kulturmedium sein, in dem die Embryonen außerhalb des Uterus entwickelt werden.

Dabei ist zu bedenken, dass negative Umwelteinflüsse über die Plazenta gleichzeitig sowohl auf den Feten (F1-Generation) einwirken als auch darüber hinaus auf seine Keimzellen, aus denen später die Enkelgeneration (F2-Generation) heranwächst ( $>$ Abb. 9 ).

Cave

Das bedeutet, dass Faktoren während der Schwangerschaft nicht unbedingt an die Nachkommen „vererbt“ werden, aber im Embryo bzw. Feten zu einer epigenetisch bedingten „Fehlprogrammierung“ von Regelsystemen führen können, von der dann auch die Gonaden - und damit die übernächste Generation betroffen sein können.

MATERNALE EPIGENETISCHE BEEINFLUSSUNGSFAKTOREN

Zu den maternalen Umgebungsfaktoren, die das fetale Epigenom negativ beeinflussen können, zählen:

- mütterlicher Stress

- Zufuhr bestimmter chemischer Substanzen (z. B. BPA, Phtalate, einige Medikamentenwirkstoffe, Drogen, Alkohol)

- Rauchen

- pathologische Stoffwechselsituation

- inadäquate Nährstoffversorgung der Schwangeren 


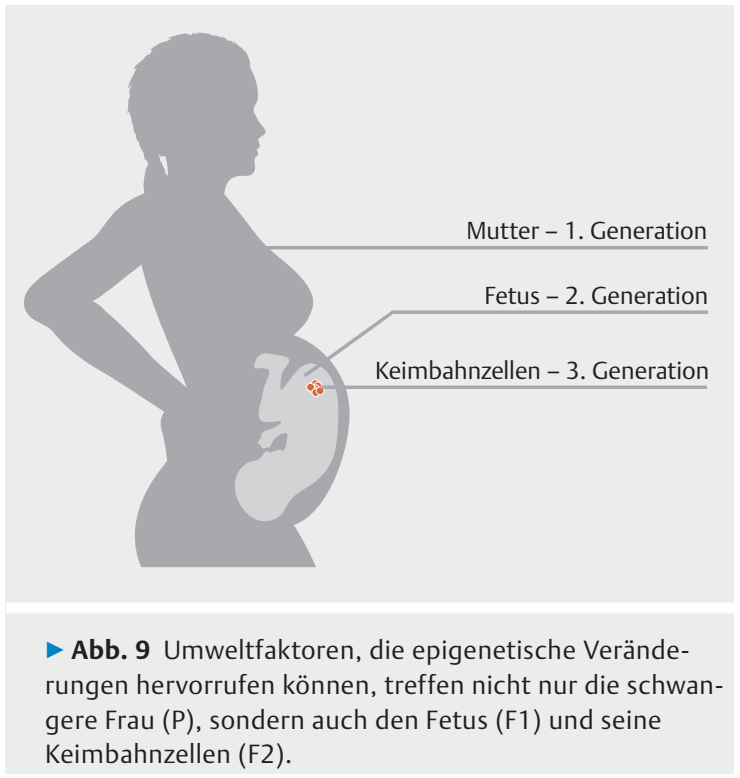

Von Bedeutung ist dabei auch, zu welchem Zeitpunkt in der Schwangerschaft ein negativer Faktor auf das ungeborene Kind einwirkt: von Beginn an, über einen bestimmten Zeitraum (im 1., 2. oder 3. Trimester) oder innerhalb eines sehr kurzen Zeitfensters.

Von einer Vererbung epigenetischer Merkmale im klassischen Sinne ist dann auszugehen, wenn die Veränderung bei den Nachkommen auch über die F2-Generation hinaus beobachtet werden kann, obwohl der auslösende Umweltreiz nur innerhalb eines kurzen Zeitfensters während der Schwangerschaft in der 1. Elterngeneration einwirken konnte.

\section{Merke}

Ein Umweltfaktor innerhalb eines bestimmten Zeitfensters der Schwangerschaft kann auf 3 Generationen einwirken: auf die Mutter (P), den Fetus (F1) und die Keimzellen (F2).

\section{Stress}

Radtke et al. konnten nachweisen, dass Kinder, deren Mütter während der Schwangerschaft traumatisierende Gewalt durch ihren Partner erfahren hatten, im juvenilen Alter ein verändertes Methylierungsmuster am Gen des Glukokortikoid-Rezeptors aufwiesen, das mit einer erhöhten Kortisolausschüttung einherging. Die Autoren schließen daraus auf eine fetale Umprogrammierung der Hypothalamus-Hypophysen-Nebennierenrinden-Achse (HPA-Achse) [8].
Tierversuche zeigen ähnliche Ergebnisse und liefern Hinweise, dass extremer mütterlicher Disstress zu fetalen epigenetischen Fehlprogrammierungen führen kann. Man vermutet hier einen Zusammenhang mit der Entwicklung von emotionalen Störungen und Verhaltensauffälligkeiten sowie neuronalen Erkrankungen wie z.B. Depressionen und Schizophrenie, wobei die Mechanismen noch nicht geklärt sind.

Synthetische Glukokortikoide werden in der Schwangerschaft bei drohender Frühgeburt zur schnelleren Lungenreifung eingesetzt. Es gibt Hinweise im Tierversuch, dass dies einen ähnlichen Effekt wie extremer mütterlicher Stress haben kann: männliche Nachkommen von Muttertieren, die während der Tragzeit mit künstlichen Stresshormonen behandelt wurden, zeigten bis in die Enkelgeneration hinein epigenetische Veränderungen, die denen nach starkem mütterlichen Stress ähnlich waren [9].

\section{Merke}

Extrem negative Erfahrungen während der Schwangerschaft können beim Feten durch epigenetische Veränderungen zur Umprogrammierung der Stressachse führen und möglicherweise das spätere Risiko für die Entwicklung von emotionalen Störungen und Verhaltensauffälligkeiten erhöhen.

\section{Rauchen}

Rauchen in der Schwangerschaft führt zu epigenetischen Veränderungen beim menschlichen Feten, die nachweislich negative gesundheitliche Auswirkungen auf die spätere Funktion von Lunge und Immunsystem haben können.

Bei Neugeborenen von Müttern, die während der Schwangerschaft geraucht hatten, fanden Markunas et al. ein verändertes DNA-Methylierungsmuster in den Blutzellen [10].

Forscher des Deutschen Krebsforschungszentrums in Heidelberg wiesen im Blut von Neugeborenen rauchender Mütter epigenetische Veränderungen nach, die bis ins 5. Lebensjahr vorhanden waren und in direktem Zusammenhang mit einem erhöhten Risiko für asthmaähnliche Anfälle stehen [11].

Sowohl im Blut rauchender Mütter als auch im Nabelschnurblut wurde ein erhöhter Anteil bestimmter epigenetischer Botenmoleküle gefunden, die eine regulatorische Funktion bei der Immunantwort übernehmen. Dies ging bei den Kindern mit einem erhöhten Allergierisiko in den ersten 3 Lebensjahren einher [12]. 


\section{Chemische Substanzen}

Die Exposition zu bestimmten chemischen Substanzen während kritischer Entwicklungsphasen kann negative Auswirkungen haben auf:

- neuronale Entwicklung

- Fruchtbarkeit

- Übergewicht

- Immunfunktion

- Krebsrisiko

Das Auftreten zugrunde liegender epigenetischer Veränderungen wird derzeit untersucht.

In Tierversuchen zeigte beispielsweise der Plastikinhaltsstoff Bisphenol A negative epigenetische Auswirkungen vor allem auf das Gehirn mit Auswirkungen auf die Lern- und Gedächtnisleistungen. Bei Nachkommen von Mäusen, die während der Schwangerschaft teils sehr geringen Mengen BPA ausgesetzt waren, wurden Verhaltensänderungen beobachtet, die dosisabhängig und geschlechtsspezifisch unterschiedlich ausgeprägt waren [13].

\section{Intrauterine Mangelversorgung}

Die „Thrifty Phenotype Hypothesis“ besagt, dass ein reduziertes fetales Wachstum aufgrund einer Mangelversorgung im späteren Leben mit dem Auftreten chronischer Erkrankungen assoziert ist, wie koronare Herzkrankheit, Hypertonie und Diabetes [14]. Man geht davon aus, dass aufgrund einer inadäquaten Nährstoffversorgung eine fetale Fehlprogrammierung im Uterus stattfindet, die den neu entstandenen Organismus dauerhaft „prägt“ und langfristig zu gesundheitlichen Problemen führen kann.

Merke

Die „Thrifty Phenotype Hypothesis“ geht davon aus, dass nach intrauteriner Mangelernährung aufgrund einer fehlerhaften fetalen Programmierung ein erhöhtes Risiko für die spätere Entwicklung von bestimmten chronischen Erkrankungen besteht.

Ein Teil der durch einen intrauterinen Mangel bedingten Veränderungen im Organismus, die zu Fehlprogrammierungen führen, geht mit epigenetischen Vorgängen einher. Verschiedene Studien an Populationen, die aufgrund von Kriegen Hungersnöten ausgesetzt waren, bestätigen einen Zusammenhang zwischen einer extremen Mangelernährung während verschiedener Zeitfenster in der Schwangerschaft und langfristig veränderter DNA-Methylierung sowie dem vermehrten Auftreten von Erkrankungen bei den Nachkommen, die bis in die Enkelgenerationen reichen $[15,16]$.
INTRAUTERINE MANGELVERSORGUNG

Zu niedriges Geburtsgewicht als Indikator für intrauterine Mangelernährung

Ein in Abhängigkeit vom Schwangerschaftsalter niedriges Geburtsgewicht gilt als Indikator für eine Mangelsituation in utero. Ende der 1980er Jahre entdeckte der britische Epidemiologe Barker einen Zusammenhang zwischen niedrigem Geburtsgewicht und dem späteren Auftreten von chronischen Erkrankungen wie koronarer Herzkrankheit, Hypertonie, Diabetes mellitus Typ 2 sowie Schlaganfall. Er ging davon aus, dass sich der Fetus durch Anpassung an seine Umgebung auf das spätere Leben vorbereitet und formulierte die These, dass eine intrauterine Mangelernährung zu einer fehlerhaften fetalen Programmierung führt.

Von den Anpassungsprozessen betroffen sind auch epigenetische Veränderungen, die die Genexpression beeinflussen. Weitere Mechanismen finden auf Zell- und Organebene statt, hierzu zählen z. B. eine Veränderung der Mitochondrienfunktion und der Organstruktur.

Die Ursachen für ein zu niedriges Gewicht des Kindes bei seiner Geburt liegen in vielen Ländern derzeit weniger in einer Kalorien- oder Nährstoffunterversorgung der Mutter selbst. Ursächlich zugrunde liegen eher pathologische Veränderungen an der Plazenta mit unterschiedlicher Genese (z. B. Rauchen, bestimmte Erkrankungen wie Gestose, HELLP etc.), die zu einer Nährstoffunterversorgung des Ungeborenen und damit einem mangelhaften Wachstum führen.

\section{Intrauterine Überversorgung}

Immer häufiger tritt dagegen bei schwangeren Frauen in westlichen Ländern, aber auch in Schwellenländern, die gegenteilige Situation auf: eine pathologische maternale Stoffwechselsituation als Folge von (massivem) Übergewicht oder im Rahmen eines manifesten Gestationsdiabetes. In diesen Fällen wird das Kind in utero durch ein verändertes Nährstoffangebot nicht mangelsondern überernährt, in dem es erhöhten Konzentrationen ausgesetzt ist von:

- Glukose

- freien Fettsäuren

- Aminosäuren

Dadurch steigt seine Wahrscheinlichkeit für ein zu hohes Geburtsgewicht. Eine Makrosomie beim Neugeborenen als Zeichen für eine metabolische Fehlprogrammierung geht einher mit zahlreichen Risiken für Mutter und Kind.

Sowohl maternales Übergewicht als auch ein Gestationsdiabetes führen zu Veränderungen beim Fetus, die seinen Stoffwechsel im Sinne einer fetalen Programmierung prägen und auch langfristig bestehen bleiben können. 
PRÄVALENZ VON ÜBERGEWICHT UND GESTATIONSDIABETES BEI SCHWANGEREN FRAUEN IN DEUTSCHLAND

Fast jede 3. Frau startet mittlerweile übergewichtig (BMI $>25 \mathrm{~kg} / \mathrm{m}^{2}$ ) in die Schwangerschaft, vor 25 Jahren betrug der Anteil nur ca. 10\%. Dabei hat sich insbesondere der Anteil der Schwangeren mit einer Adipositas erhöht (Grad I: BMI bis $35 \mathrm{~kg} / \mathrm{m}^{2}$, Grad II: BMI bis $40 \mathrm{~kg} / \mathrm{m}^{2}$, Grad III: BMI $>40 \mathrm{~kg} / \mathrm{m}^{2}$ ). Auch ein Gestationsdiabetes wird mit steigender Tendenz diagnostiziert, derzeit sind mehr als $4 \%$ der Schwangeren betroffen (Datenerhebung im Zeitraum von 2009-2014 durch das AQUA-Institut). International schwanken die Angaben zur Prävalenz des Gestationsdiabetes, in einigen Ländern sind bis zu $20 \%$ der Schwangeren betroffen.

\section{Merke}

Die betroffenen Kinder haben u. a. selbst ein erhöhtes Risiko, später übergewichtig zu werden.

Man geht derzeit davon aus, dass diese Neigung auch auf veränderten epigenetischen Mechanismen beruht, die in der Folge zu Fehlprogrammierungen führen. Erkenntnisse der beim Feten auftretenden epigenetischen Veränderungen (in Abhängigkeit vom maternalen Stoffwechsel) liefern neue Erklärungsansätze für den starken Anstieg der Prävalenz von Übergewicht in der Bevölkerung und dem seit einigen Jahren immer häufiger diagnostizierten Gestationsdiabetes.

\section{Übergewicht und Adipositas in der Schwangerschaft} Plagemann et al. konnten nachweisen, dass eine perinatale Überernährung bei neugeborenen Rattenbabys, die noch als unreif gelten, zu einer Hypermethylierung im Promotorbereich wichtiger Gene im Hypothalamus führte, die das Körpergewicht regulieren. Durch die Veränderung in einem übergeschalteten zentralnervösen Regulationszentrum wurden das Hunger- und Sättigungsgefühl und infolgedessen die Nahrungsaufnahme negativ beeinflusst und gingen längerfristig mit einer übermäßigen Gewichtszunahme einher [17].

In Blutzellen von Kindern adipöser Mütter wurden an zahlreichen Genen Veränderungen der Methylierung gefunden. Bei einigen von ihnen ist bekannt, dass sie auch am Stoffwechsel und der Entstehung typischer Erkrankungen von Übergewichtigen beteiligt sind. Hatten die gleichen Mütter einen Magen-Bypass erhalten, waren die später geborenen Geschwister von den Veränderungen nicht betroffen [18].

Es wird auch diskutiert, dass Kinder von stark adipösen Schwangeren aufgrund epigenetischer Veränderungen möglicherweise ein erhöhtes Risiko haben, an neuronalen Erkrankungen zu leiden, die mit entzündlichen Prozessen einhergehen:
- Morbus Alzheimer

- Morbus Parkinson

- Diabetes mellitus Typ 2

- Herzinfarkt

- Schlaganfall

Im Tierversuch besteht das Risiko auch dann fort, wenn der Nachwuchs sich gesund ernährt und normalgewichtig bleibt [19].

\section{Gestationsdiabetes}

Beim Gestationsdiabetes (GDM) sind sowohl der mütterliche als auch der plazentare und fetale Metabolismus stark verändert. Ein unbehandelter hyperglykämischer Stoffwechsel der Mutter führt während der Schwangerschaft dazu, dass über die Plazenta eine massive Glukosezufuhr zum Kind stattfindet. Für das Kind geht damit ein erhöhtes Risiko für die Entwicklung von Übergewicht, Diabetes mellitus Typ 2 und weitere gesundheitliche Probleme einher.

Die mit einem Gestationsdiabetes einhergehenden epigenetischen Veränderungen sind vielfältig und werden derzeit im Rahmen einer Studie (PREG) am HelmholtzZentrum der Universität Tübingen untersucht. Durchgeführt werden genomweite DNA-Methylierungsanalysen und mRNA-Expressionsanalysen von mütterlichen und fetalen Bereichen der Plazenta. In ersten Ergebnissen konnten Kandidatengene definiert werden, bei denen ein Gestationsdiabetes mit einer veränderten Methylierung und Expression einherging [20].

\section{Einflüsse von bestimmten Nährstoffen auf die fetale DNA-Methylierung}

Neben der Quantität spielt auch die Qualität der Nährstoffzufuhr zum Feten während der Schwangerschaft eine entscheidende Rolle und kann über epigenetische Mechanismen die langfristige Gesundheit der Nachkommen beeinflussen.

Ein sichtbar nachvollziehbares Beispiel für die Steuerung epigenetischer Mechanismen durch Ernährungsfaktoren konnten Lycko et al. durch Untersuchungen an Honigbienen nachweisen [21]. Sie beobachteten, dass alle jungen Bienen nach dem Schlüpfen zunächst mit dem Futtersaft Gelée Royal versorgt wurden. Danach wurden die späteren Arbeiterinnen ausschließlich mit einem Honig-Pollen-Brei gefüttert, durch dessen Inhaltsstoffe bestimmte Gene stark methyliert und dadurch deaktiviert wurden. Nur die zukünftigen Königinnen erhielten weiterhin zusätzlich das Gelée Royal, das eine Fettsäure enthält, die die Inaktivierung der Gene verhindert ( $>$ Abb. 10). Auf diese Weise konnten nur diese auserwählten jungen Bienen die gewünschten Ei- 
genschaften einer Königin entfalten, obwohl alle Bienen identische Genomsequenzen besaßen. Die Studienergebnisse zeigten, dass im Gehirn der Königinnen mehr als 500 Gene durch Methylierung anders markiert waren als bei den Arbeiterinnen.

Studien zeigen, dass auch bei Säugetieren die DNA-Methylierung sowohl durch eine restriktive als auch eine exzessive Zufuhr bestimmter Nahrungsbestandteile beeinflussbar ist. Näher untersucht wurden Einflüsse von Protein, Fett und Kalorien sowie des Gehalts an Methyldonatoren in der Nahrung, vor allem an Nagern, Schweinen und im Humanmodell.

\section{Methyldonatoren}

In den letzten Jahren wurde eine Vielzahl verschiedener Studien im Tier- und Humanmodell durchgeführt, in denen der Einfluss einer folsäure- bzw. methylreichen Ernährung der Mutter während der Schwangerschaft auf die DNA-Methylierung und die Genexpression bei den Nachkommen untersucht wurde.

In nahezu allen Studien wurden Auswirkungen beobachtet, die jedoch variierten. Dabei scheint die Veränderbarkeit der DNA-Methylierung durch eine methylreiche Ernährung organspezifisch zu sein. Häufig wurden auch geschlechtsabhängig unterschiedliche Reaktionen auf eine Veränderung der Nährstoffanteile beobachtet.

So kann beispielsweise eine hohe Zufuhr von Methyldonatoren während kritischer Entwicklungsphasen in utero möglicherweise auch die Expression von Genen, die die Immunantwort regulieren, negativ beeinflussen und damit das Erkrankungsrisiko für allergische Atemwegserkrankungen erhöhen. Im Mausmodell wurde beobachtet, dass eine methylreiche Diät während der Schwangerschaft in der ersten Generation der Nachkommen die Expression eines Gens verändert, welches eine Rolle bei der Entstehung von allergischen Atemwegserkrankungen spielt; die Behandlung mit einer demethylierenden Substanz (5-Azacytidine) konnte die Veränderung rückgängig machen [22].

Im Mausmodell ging eine methylreiche Ernährung während der Schwangerschaft bei adulten weiblichen Nachkommen im Hypothalamus mit einer erhöhten globalen DNA-Methylierung und veränderten Genexpression einher (eigene Arbeiten, Daten unpubliziert).

Am bekannten Modell der Agouti-Maus konnte eindrucksvoll gezeigt werden, dass eine methylreiche Ernährung der Muttertiere gezielt die Genexpression der Embryos durch eine Veränderung der Methylierung und dadurch den Phänotyp der Nachkommen langfristig beeinflussen kann [23]. Das Agouti-Gen kodiert für ein parakrines Signalmolekül und wird reguliert durch

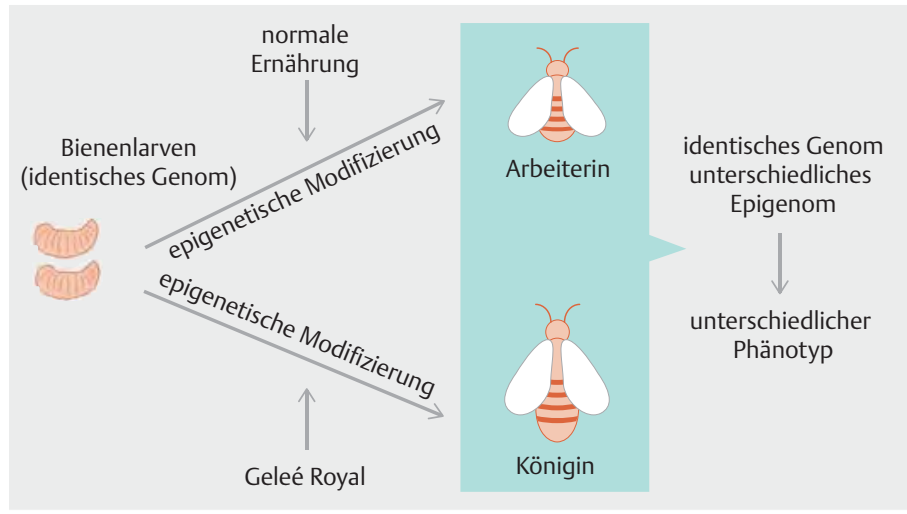

- Abb. 10 Die durch verschiedene Nahrung (Gelée Royal) bedingten epigenetischen Veränderungen führen bei der Entwicklung der Honigbiene trotz gleicher DNA-Sequenz entweder zum Phänotyp Arbeiterin oder Königin. Ursache für diese natürliche Differenzierung scheint ein Methyltransferase-Inhibitor zu sein.

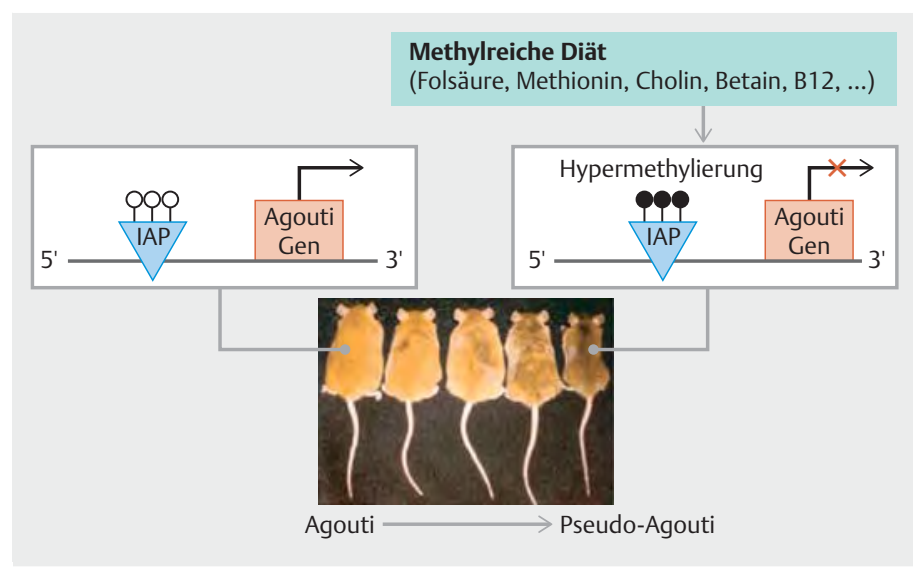

- Abb. 11 Genetisch identische Nachkommen von Mäusen, die 5 verschiedene Phänotypen repräsentieren (modifiziert nach [24] Dolinoy D, Weidman J, Waterland R et al. Maternal genistein alters coat color and protects Avy mouse offspring from obesity by modifying the fetal epigenome. Environ Health Perspect 2006; 114 (4):567 - 72. Gelbes Fell: Hypomethylierung an der IAP-Sequenz vor dem Agouti-Gen, wodurch eine maximale ektope Genexpression ermöglicht wird. Geflecktes/braunes Fell: Hypermethylierung an der IAP-Sequenz legt die ektope Agouti-Expression in unterschiedlichem Ausmaß still; die Fellfarbe gibt das Niveau der DNA-Methylierung wieder. Mäuse mit verstärkt gelber Fellfarbe sind darüber hinaus übergewichtiger. Foto mit freundlicher Genehmigung von D. Dolinoy.

die Promotoraktivität eines bestimmten Genabschnitts, der Intracisternal-A-Particle-Sequenz (IAP).

Agouti- Mäuse, die das viable yellow Allel des AgoutiGens (Avy/a) besitzen, leiden häufiger an krankhaftem Übergewicht, Diabetes mellitus Typ 2 und Krebs und haben eine gelbe Fellfarbe. Zugrunde liegt die Insertion eines IAP-Retrotransposons vor dem Agouti-Gen, seine Transkription ruft an dieser Stelle eine ektope Expression des Agouti-Proteins hervor, dessen parakrine Signalfunktion dann in den verschiedenen Geweben zu den phänotypischen Veränderungen führt. 


\section{SYNTHETISCHE FOLSÄURE}

Das synthetisch hergestellte Folsäuremolekül ist voll oxidiert und chemisch sehr stabil. Es kann direkt ohne Umwandlungsprozesse über die Darmschleimhaut resorbiert werden; die individuelle Bioverfügbarkeit liegt zwischen $50 \%$ und $97 \%$ und ist im Mittel höher als die der natürlich vorkommenden Nahrungsfolate. Diese sind sehr labil gegenüber äußeren Einflüssen; sie liegen größtenteils in reduzierter Form vor und müssen vor der enteralen Resorption umgewandelt werden. Für eine Supplementierung in Präparatform sowie für die Anreicherung von Lebensmitteln wird daher synthetische Folsäure verwendet.

Eine auf den Zeitraum der Schwangerschaft beschränkte methylreiche Diät führte in der F1-Generation während der frühen Embryogenese zu einer verstärkten Methylierung von CpG-Islands der IAP-Sequenz und dadurch zu deren Stilllegung. Diese blieb langfristig bestehen mit der Folge, dass die Nachkommen eine im Vergleich dunklere Fellfarbe hatten und gesund waren ( Abb. 11).

Es konnte gezeigt werden, dass es sich hier um eine unvollständige Löschung der epigenetischen Markierungen während der Reprogrammierung in den Keimzellen handelt, die auf diese Weise von der Mutter an die Nachkommen weitergegeben wird. Die veränderte Methylierung blieb auch bestehen, nachdem der Nachwuchs postnatal eine normale Nahrung erhielt. Sie wurde mit sukzessiv abnehmendem Ausprägungsgrad an die Folgegenerationen weitergegeben.

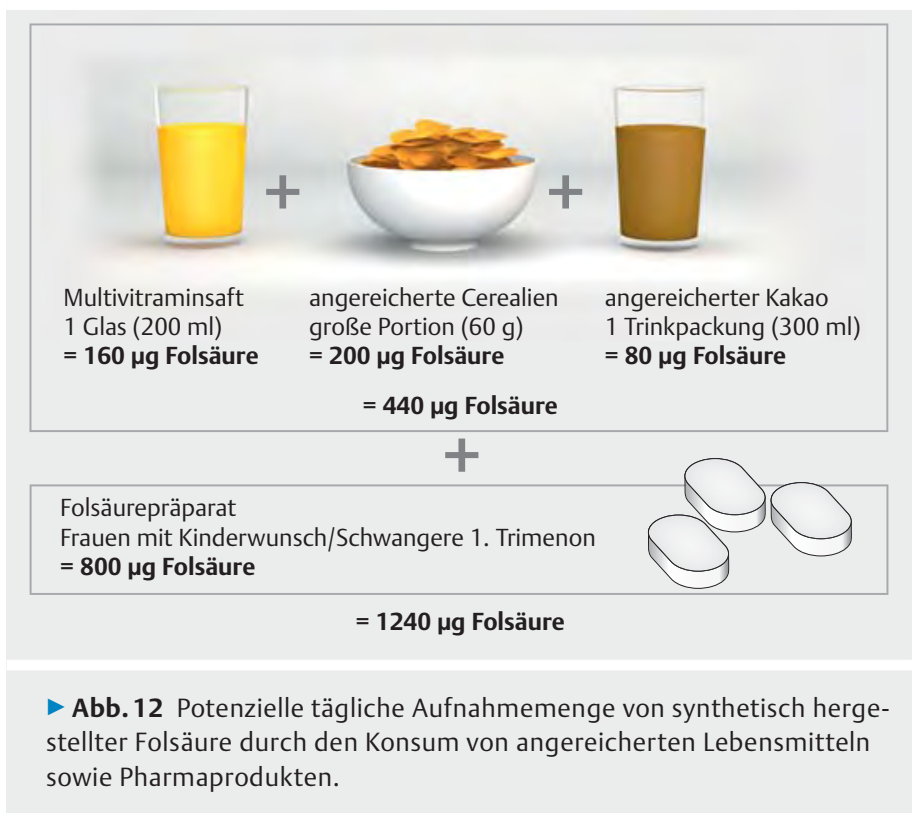

\section{Merke}

Eine methylreiche Ernährung der Mutter während der Schwangerschaft kann demnach offenbar - zumindest im Tiermodell - die embryonalen Reprogrammierungsvorgänge und damit die Etablierung neuer Methylierungsmuster auch in der Keimbahn des Ungeborenen verändern.

\section{Besondere Rolle der Folsäure}

Die Entdeckung, dass mit der Nahrung zugeführte Methyldonatoren zu epigenetischen Veränderungen führen können, die während der Schwangerschaft potenziell auch den Feten betreffen, führt zu einer kritischen Betrachtung der Aufnahmemengen insbesondere von synthetischer Folsäure.

Schwangeren sowie Frauen in gebärfähigem Alter bzw. mit Planung einer Schwangerschaft wird empfohlen, zusätzlich zu einer folatreichen Ernährung perikonzeptionell $400 \mu \mathrm{g}$ Folsäure täglich als Prophylaxe zu supplementieren, um das Risiko für die Entstehung von Neuralrohrdefekten (NRD) zu minimieren. Dies ist insofern schwierig zu erreichen, da bei vielen Frauen erst nach einigen Wochen die Schwangerschaft festgestellt wird. In der Praxis wird die Supplementierung nicht selten erst ab diesem Zeitpunkt begonnen und dann über den gesamten Zeitraum der Schwangerschaft sowie möglicherweise auch in der Stillzeit fortgeführt.

Um das Niveau der Folsäureversorgung in der Gesamtbevölkerung gezielt anzuheben, wurde in einigen Ländern seit Ende der 1990er Jahre die obligatorische Anreicherung von Grundnahrungsmitteln mit Folsäure eingeführt. Darüber hinaus werden mittlerweile viele Lebensmittel (u.a. Cerealien, Müsli, Getränke), die mit Multivitaminen angereichert sind, auf den Markt gebracht.

Die Aufnahmemenge von synthetischer Folsäure kann daher in Einzelfällen stark erhöht sein. In > Abb. 12 ist beispielhaft aufgeführt, wie die tägliche Zufuhr von Folsäure durch den Verzehr angereicherter Lebensmittel sowie die zusätzliche Einnahme von pharmazeutisch hergestellten Nahrungsergänzungsmitteln insbesondere bei Schwangeren potenziell einen sehr hohen Wert erreichen kann.

\section{Cave}

Mit Folsäure angereicherte Lebensmittel sollten nicht unkritisch verzehrt werden, da unter Umständen sehr hohe Mengen aufgenommen werden können. 


\section{Besondere Situation im fetalen Kreislauf}

Im normalen postnatalen Kreislauf werden die Nährstoffe oral aufgenommen und müssen zunächst über den Darm resorbiert werden, ehe sie in den Blutkreislauf gelangen. Verschiedene Rezeptoren sowie die Verfügbarkeit des Vitamins $B_{12}$ regulieren die Aufnahmekapazität der mit der Nahrung zugeführten Folate bzw. der synthetisch hergestellten Folsäure.

Im Unterschied dazu wird die Folsäure während der Schwangerschaft über das mütterliche Blut gemeinsam mit den anderen Nährstoffen über die Plazenta zum heranreifenden Ungeborenen transportiert und gelangt über die Nabelvene direkt in den fetalen Blutkreislauf. Dementsprechend findet intrauterin keine vorgeschaltete Regulation der Folsäurezufuhr durch Dünndarm (als limitierender Resorptionsfaktor), Leber (als Zwischenspeicher) und Niere (als Ausscheidungsorgan) statt, so dass zu diesem Zeitpunkt eine kontrollierte Herstellung einer Homoöstase nicht gegeben ist.

Die beiden verschiedenen Resorptionsmechanismen und -orte sind in $\mathbf{A b b} \mathbf{1 3}$ dargestellt.

\section{Merke \\ Verschiedene Studien geben Anlass zu der Vermu- tung, dass durch die Aufnahme unphysiologisch ho- her Mengen synthetischer Folsäure epigenetische Veränderungen beim Feten auftreten, die im weite- ren Verlauf negative gesundheitliche Auswirkungen haben könnten.}

In einer Untersuchung an Lymphoblasten wurde beobachtet, dass in der Zellkultur eine Vielzahl von Genen in Abhängigkeit von der Folsäurekonzentration im Medium dysreguliert wird, darunter auch Gene, die dem Imprinting unterliegen, wie z. B. das Xist-Gen [25]. Die Autoren warnen davor, dass eine Folsäuresupplementierung während der Schwangerschaft zu einer anormalen Genexpression während der frühen Hirnentwicklung führen könnte, mit langfristigen Folgen für Prozesse der Kognition und Wahrnehmung.

Cho et al. beobachteten an Ratten, dass eine maternale Folsäuresupplementierung ausschließlich während der Tragzeit im weiteren Verlauf bei den untersuchten männlichen Nachkommen zu einer gesteigerten Nahrungsaufnahme führte; sie entwickelten im weiteren Verlauf eine Neigung zu Fettleibigkeit [26]. Bei den Nachkommen, die auch postnatal folsäurereich ernährt wurden, entwickelte sich das Körpergewicht demgegenüber normal. Es konnte gezeigt werden, dass sowohl eine ausschließlich pränatal verabreichte als auch eine dauerhaft fortgeführte Folsäuresupplementierung bei den Nachkommen langfristig mit einer veränderten hypothalamischen Expression von Genen einherging,

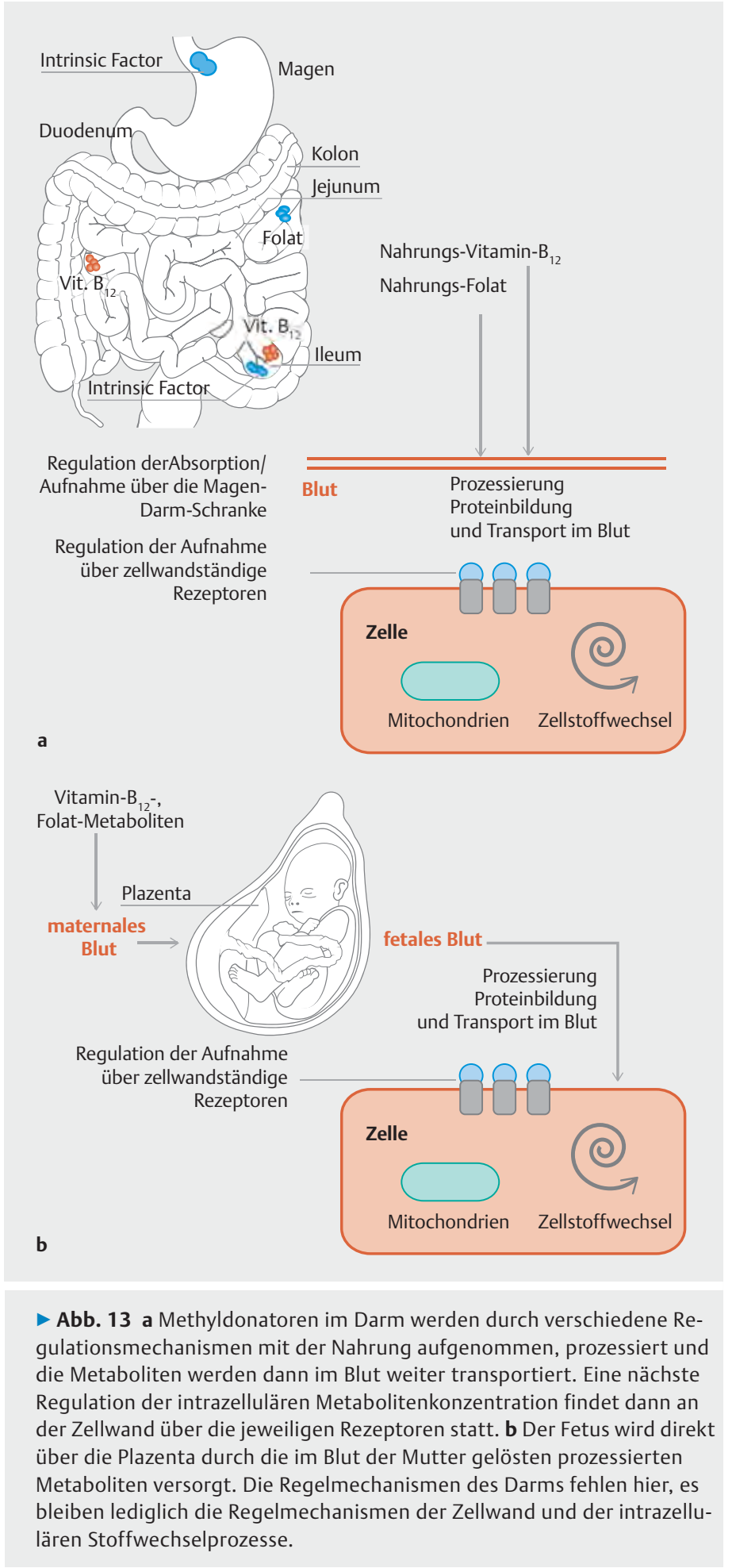

die eine Rolle hinsichtlich der Regulation der Nahrungsaufnahme spielen [27].

Diese Beobachtungen weisen darauf hin, dass durch die methylreiche Diät zu einem kritischen Zeitpunkt der intrauterinen Entwicklung in einem übergeordneten Regelzentrum epigenetische Veränderungen statt- 
gefunden haben, die sich auf Abläufe im gesamten Organismus auswirken.

\section{Cave}

Es besteht das Risiko, dass von außen in die Etablierung von Regelkreisen eingegriffen wurde und eine fetale (Fehl-)Programmierung stattgefunden hat, die sich dauerhaft auswirkt.

Eine Veränderung der fetalen Genregulation durch nutritive Faktoren zu einem sehr frühen Zeitpunkt, die auch an spätere Folgegenerationen weitergegeben werden kann, verleiht der Bedeutung der Ernährung in der Schwangerschaft eine neue Dimension, die möglicherweise weit in die gesundheitliche Zukunft der Nachkommen reicht.

\section{Langfristige Auswirkungen epigenetischer Veränderungen im Fokus}

Die langfristigen Auswirkungen intrauteriner negativer Einflüsse auf die Gesundheit der Nachkommen werden unter dem Begriff „DOHaD“ (Developmental Origin of Health and Disease) zusammengefasst. Sie sind Gegenstand zahlreicher Untersuchungen und haben im Jahr 2004 zu der Neugründung der gleichnamigen internationalen Fachgesellschaft geführt.

Man geht mittlerweile davon aus, dass viele Erkrankungen, die im Laufe des Lebens auftreten, ihren Ursprung in der Phase des intrauterinen Wachstums haben. Epigenetische Modifikationen wie die DNA-Methylierung, ausgelöst z. B. durch eine inadäquate Versorgung des Fe-

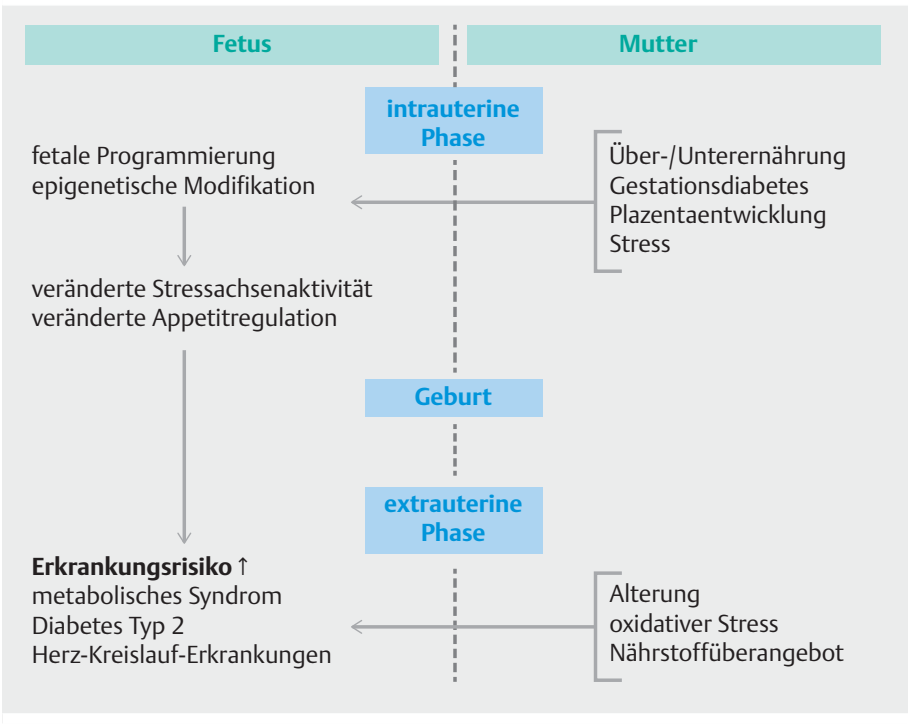

- Abb. 14 Schematische Darstellung des Zusammenhangs zwischen der Nährstoffexposition während der Schwangerschaft und den Mechanismen, die zum Auftreten von Krankheiten im späteren Leben führen. tus durch einen Nährstoffmangel oder -überschuss, stellen einen der Mechanismen dar, die zu einer fehlerhaften fetalen Programmierung führen und später mit einem erhöhten Risiko, z. B. für das metabolische Syndrom, einhergehen. In $>$ Abb.14 ist der Zusammenhang zwischen intrauteriner Fehlprogrammierung, epigenetischer Modifikation und Erkrankungsrisiko schematisch dargestellt.

Bisherige Studien konzentrierten sehr stark sich auf Umgebungsfaktoren, die über die Mutter an das Ungeborene vermittelt werden und seine gesundheitliche Entwicklung langfristig beeinflussen können.

\begin{abstract}
Merke
Vor dem Hintergrund der beschriebenen Erkenntnisse ist es unbestritten, dass ein ungünstiger maternaler Lebensstil einen negativen Einfluss auf das fetale Epigenom ausüben kann.
\end{abstract}

Zigaretten- und Alkoholkonsum, die Gewichtsregulierung sowie eine ausreichende Aufnahme von Nährstoffen zählen dabei zu den Lebensstilfaktoren, die bewusst durch die Mutter beeinflussbar sind.

In einem 2014 veröffentlichten Kommentar wiesen Richardson et al. darauf hin, dass mit den Erkenntnissen auf dem Gebiet der Epigenetik im Hinblick auf die Schwangerschaft in der Öffentlichkeit sorgfältig umgegangen werden sollte: Vermieden werden sollte ein zu starker negativer Druck, der durch einseitige Medienberichte auf die werdenden Mütter ausgeübt werden und möglicherweise Schuldgefühle und Ängste hervorrufen könnte [28].

Insbesondere die Gesellschaft ist hier auch in der Verantwortung, Umgebungsbedingungen zu schaffen, die der Gesundheit der zukünftigen Generationen zuträglich sind.

\section{Väterliche Einflüsse auf die fetale DNA-Methylierung}

Zunehmend wird erkannt, dass das fetale Epigenom auch durch Einflüsse, die vom Vater ausgehen, beeinflusst wird.

Ein paternales Folsäuredefizit zum Zeitpunkt der Konzeption kann über epigenetische Mechanismen einen gravierenden Einfluss auf die fetale Gesundheit ausüben und erhöhte im Tierversuch das Auftreten von Fehlbildungen. Lambrot et al. konnten sowohl bei den Spermien als auch in der Plazenta epigenetische Veränderungen identifizieren [29]. Betroffen waren auch Gene, die eine Rolle bei Entwicklungsprozessen und chroni- 
schen Erkrankungen wie Krebs, Diabetes mellitus, Autismus und Schizophrenie spielen.

Chronisch gestresste männliche Mäuse zeugten Nachkommen, deren Stressregulation verändert war. Bei den väterlichen Spermien wurde eine epigenetische Veränderung beobachtet, die die microRNAs betraf [30]. Mychasiuk et al. konnten nachweisen, dass beim Nachwuchs gestresster Rattenmännchen epigenetische Veränderung in wichtigen Gehirnzellen auftraten, die einhergingen mit Verhaltensauffälligkeiten [31].

\section{Zusammenfassung}

Das Genom besteht aus Desribonukleinsäuren, deren Sequenz in allen Zellen gleich ist und sich im Allgemeinen im Laufe des Lebens nicht verändert (Ausnahme: Spontanmutationen). Obwohl aber alle Zellen die gleiche Gensequenz haben, unterscheiden sie sich in Form und Funktion deutlich. Auch genetisch identische eineiige Zwillinge sind sich äußerlich zwar ähnlich, entwickeln sich aber im Laufe des Lebens immer mehr auseinander und bekommen auch verschiedene Erkrankungen. Erklären lässt sich das mit der Epigenetik.

Die Epigenetik gilt als das Bindeglied zwischen Umwelteinflüssen und Genen: Sie bestimmt, unter welchen Umständen welches Gen an- bzw. abgeschaltet wird und steuert so die Expression der Gene. Während das Genom also einen starren Zustand darstellt, verändert sich das Epigenom sowohl durch intrazellulläre Steuerungsvorgänge sowie durch äußere Einflüsse ständig. Es gilt also in allen Zellen in Abhängigkeit von Typ und Aktivierungszustand: Gleiches Genom, unterschiedliches Epigenom.

Zu den heute bekannten Mechanismen der Genregulation zählen:

- DNA-Methylierung an den CpG-Islands in den Promotorregionen bestimmter Gene

- Histonmodifizierung

- Regulierung der Translation durch RNA-Interferenz (RNA-Silencing)

Galten bisher auf ein Lebewesen im Laufe seines Lebens einwirkende äußere Einflüsse wie Ernährung oder Stress nur im Falle von Mutagenität bzw. Teratogenität als vererbbar, da so die Gensequenz durch Mutationen verändert wurde, weiß man heute, dass auch Faktoren wie Ernährung, Stress und Erkrankungen über Modifikationen des Epigenoms die Epigenetik der nachfolgenden Generationen beeinflusst.

Epigenetische Einflüsse prägen insbesondere während der Embryonal- und Fetalzeit sowie postnatal während der Neonatalzeit den sich entwickelnden Organismus entscheidend und haben damit Einfluss auf die Ge- sundheit des Organismus während des gesamten späteren Lebens. Daher sollten insbesondere die für diese Lebensphase verantwortlichen Disziplinen der Geburtshilfe und der Neonatologie intensive Kenntnisse über die Zusammenhänge zwischen Stoffwechsel (z. B. Gestationdiabetes) und Psyche der Mutter sowie des Neonaten (enterale/parenterale Ernährung/neurogene Bahnung) und der Möglichkeit der epigenetischen Prägung für das spätere Leben des Kindes haben.

Interessenkonflikt

Die Autoren geben an, dass kein Interessenkonflikt besteht.

\section{Über die Autoren}

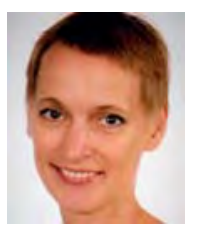

\section{Bettina Brune}

Dr. rer. nat. 1993-1996 Ausbildung zur Kinderkrankenschwester am Universitätsklinikum Münster. 1999-2008 Studium der Ökotrophologie an den Hochschulen Münster und Anhalt. 2011-2013 Frühgeborenen-Nachsorge-Kinderklinik, Klinikum Lippe/Detmold. 2009-2015 Gastwissenschaftlerin Universitätskinderklinik Magdeburg/Promotionsarbeit Universität Paderborn. Seit 2017 Leitung der Diät- und Milchküche sowie Ernährungsberatung in der Neonatologie, Klinik für Kinder und Jugendmedizin, Klinikum Lippe/Detmold.

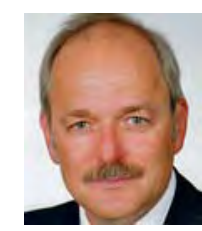

\section{Thomas Brune}

Prof. Dr. med. 1977-1985 Studium der Humanmedizin an der Westfälischen-Wilhelms-Universität (WWU) Münster, 1985 Promotion. 1985-1987 Institut für Molekularbiologie der Blutgerinnung WWU Münster. 1987-1991 Behringwerke AG Marburg, Forschung Immunologie. 1991-1992 Institut für Transfusionsmedizin, WWU Münster. 1992-1994 Institut für Klinische Chemie und Laboratoriumsmedizin, Universitätsklinikum Regenburg. 1994-2002 Universitätskinderklinik Münster, 2003 Habilitation. 2002-2010 Universitätskinderklinik Magdeburg. Seit 2011 Chefarzt der Klinik für Kinder und Jugendmedizin, Klinikum Lippe/Detmold.

Korrespondenzadresse

Bettina Brune

Klinik für Kinder- und Jugendmedizin

Klinikum-Lippe/Detmold

Röntgenstrasse 18

32756 Detmold

E-Mail: Bettina.Brune@klinikum-lippe.de 
Literatur

[1] Waddington C. The Epigenotype. Int ] of Epidemiol 2012; 41: $10-13$

[2] FAO/WHO. FAO/WHO. Expert Consultation on human vitamin and mineral requirements: Folate and folic acid. Rom: FAO; 2001: $53-62$

[3] Gordon L, Joo J, Powell J et al. Neonatal DNA methylation profile in human twins is specified by a complex interplay between intrauterine environmental and genetic factors, subject to tissue-specific influence. Genome Res 2012; 22: $1395-1406$

[4] Matsuda M, Yasutomi M. Inhibition of cephalic neural tube closure by 5 -azacytidine in neurulating rat embryos in vitro. Anat Embryol 1992; 185: 217-223

[5] Hackett J, Surani M. DNA methylation dynamics during the mammalian life cycle. Philos Trans R Soc Lond B Biol Sci 2013; 368(1609): 20110328

[6] Gicquel C, Gaston V, Mandelbaum J et al. In-vitro-fertilization may increase the risk of Beckwith-Wiedemann Syndrome related to the abnormal imprinting of the KCNQ10T gene. Am J Hum Genet 2003; 72: 1338 -1341

[7] Zhao J, Goldberg J, Bremner J et al. Global DNA methylation is associated with insulin resistance: a monozygotic twin study. Diabetes 2012; 61: $542-546$

[8] Radtke K, Ruf M, Gunter H et al. Transgenerational impact of intimate partner violence on methylation in the promotor of the glucocorticoid receptor. Transl Psychiatry 2011; 1: e21

[9] Crudo A, Petropoulos S, Moisiadis V et al. Prenatal synthetic glucocorticoid treatment changes DNA methylation states in male organ systems: multigenerational effects. Endocrinology 2012; 153: 3269-3283

[10] Markunas C, Xu Z, Harlid S et al. Identification of DNA methylation changes in newborns related to maternal smoking during pregnancy. Environ Health Perspect 2014; 122: $1147-1153$

[11] Bauer T, Trump S, Ishaque $\mathrm{N}$ et al. Environment-induced epigenetic reprogramming in genomic regulatory elements in smoking mothers and their children. Mol Syst Biol 2016; 12: 861

[12] Herberth G, Bauer M, Gasch M et al. Maternal and cord blood miR-223 expression associates with prenatal tobacco smoke exposure and low regulatory T-cell numbers. J Allergy Clin Immunol 2014; 133: $543-550$

[13] Yeo M, Berglund K, Hanna M et al. Bisphenol A delays the perinatal chloride shift in cortical neurons by epigenetic effects on the Kcc2 promotor. Proc Natl Acad Sci USA 2013; 110: $4315-4320$

[14] Hales C, Barker D. Type 2 (non-insulin-dependent) diabetes mellitus: the thrifty phenotype hypothesis. Diabetologica 1992; 35: 595-601

[15] Tobi E, Lumey L, Talens R et al. DNA methylation differences after exposure to prenatal famine are common and timingand sex-specific. Hum Mol Genet 2009; 18: 4046 - 4053

[16] Painter R, Osmond C, Gluckman P et al. Transgenerational effects of prenatal exposure to the Dutch famine on neonatal adiposity and health in later life. BJOG 2008; 115: 1243 1249

[17] Plagemann A, Harder T, Brunn M et al. Hypothalamic proopiomelanocortin promoter methylation becomes altered by early overfeeding: an epigenetic model of obesity and the metabolic syndrome. J Physiol 2009; 587: 4963-4976
[18] Guénard F, Deshaies Y, Cianflone K et al. Differential methylation in glucoregulatory genes of offspring born before vs after maternal gastrointestinal bypass surgery. Proc Natl Acad Sci USA 2013; 110: 11439-11444

[19] Bilbo S, Tsang V. Enduring consequences of maternal obesity for brain inflammation and behavior of offspring. FASEB J 2010; 24: $2104-2115$

[20] Stirm L, Salih J, Häring $\mathrm{H}$ et al. Epigenetische Veränderungen im Gestationsdiabetes. Diabetologie und Stoffwechsel 2015; 10: P191

[21] Lyko F, Foret S, Kucharski R et al. The honey bee epigenomes: differential methylation of brain DNA in queens and workers. PLos Biol 2010; 8: e1000506

[22] Hollingsworth J, Maruoka S, Boon K et al. In utero supplementation with methyl donors enhances allergic airway disease in mice. J Clin Invest 2008; 118: 3462 - 3469

[23] Waterland R, Jirtle R. Transposable elements: targets for early nutritional effects on epigenetic gene regulation. Mol Cell Biol 2003; 23: $5293-5300$

[24] Dolinoy D. The agouti mouse model: an epigenetic biosensor for nutritional and environmental alterations on the fetal epigenome. Nutr Rev 2008; 66: 7-11

[25] Junaid M, Kuizon S, Cardona J et al. Folic acid supplementation dysregulates gene expression in lymphoblastoid cellsimplications in nutrition. Biochem Biophys Res Commun 2011; 412: 688-692

[26] Cho C, Sánchez-Hernández D, Reza-López S et al. High folate gestational and post-weaning diets alter hypothalamic feeding pathways by DNA methylation in Wistar rat offspring. Epigenetics 2013; 8: 710-719

[27] Brenseke B, Prater M, Bahamonde J et al. Current thoughts on maternal nutrition and fetal programming of the metabolic syndrome. J Pregnancy 2013: 368 - 461

[28] Richardson S, Daniels C, Gillman M et al. Society: Don't blame the mothers. Nature 2014; 512: 131-132

[29] Lambrot R, Xu C, Saint-Phar S et al. Low paternal dietary folate alters the mouse sperm epigenome and is associated with negative pregnancy outcomes. Nat Commun 2013; 4: $28-89$

[30] Rodgers A, Morgan C, Bronson S et al. Paternal stress exposure alters sperm microRNA content and reprograms offspring HPA stress regulation. J Neurosci 2013; 33: 9003 9012

[31] Mychasiuk R, Harker A, Ilnytskyy S et al. Paternal stress prior to conception alters DNA methylation and behaviour of developing rat offspring. Neuroscience 2013; 241: 100-105

Bibliografie

DOI http://dx.doi.org/10.1055/s-0042-119062

Neonatologie Scan 2017; 06: 51-70

(c) Georg Thieme Verlag KG Stuttgart · New York ISSN 2194-5462 


\section{Punkte sammeln auf CME.thieme.de}

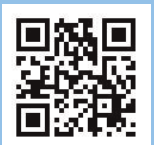

Diese Fortbildungseinheit ist 12 Monate online für die Teilnahme verfügbar.

Sollten Sie Fragen zur Online-Teilnahme haben, finden Sie unter http://cme.thieme.de/hilfe eine ausführliche Anleitung. Wir wünschen viel Erfolg beim Beantworten

der Fragen!

Unter eref.thieme.de/ZZWHL5X oder über den QR-Code kommen Sie direkt zum Artikel zur Eingabe der Antworten.

VNR 2760512017152373215

\section{Frage 1}

Welcher Vorgang gehört zur epigenetischen Regulierung der Expression eines Gens?

A Histonacetylierung
B DNA-Splicing
C Mitose
D Meiose
E Proteinbiosynthese

\section{Frage 2}

Welches Syndrom zeigt keinen Zusammenhang zum Vorgang des Imprinting?
A Prader-Willi-Syndrom (PWS)
B Angelmann-Syndrom (AS)
C Beckwith-Wiedemann-Syndrom (BWS)
D Hutchinson-Gilford-Syndrom
E Silver-Russel-Syndrom (SRS)

\section{Frage 3}

Welche Aussage zu den CpG-Inseln trifft nicht zu?

A Die CpG-Inseln liegen im Gesamtgenom überwiegend methyliert vor.

B Die CpG-Inseln liegen im Promotorbereich überwiegend methyliert vor.

C Die Methylierung des Cytosins findet bei Wirbeltieren hauptsächlich innerhalb von Cytosin-Phosphat-GuaninDinukleotiden (CpG-Dinukleotiden) statt.

D Die CpG-Inseln ermöglichen im nicht methylierten Zustand im Promotorbereich als potenzielle Bindungsstellen für Methylgruppen die Regulation der Genexpression.

E In der Regel wird die Genexpression durch Methylierung der CpG-Inseln in der Promotorregion unterdrückt.

\section{Frage 4}

Welche Lebensphase ist keine besonders sensible Lebensphase, in der die DNA-Methylierung verändert wird?
A Embryonalzeit
B Fetalzeit
C Pubertät
D mittleres Erwachsenenalter
E Seniorenalter

\section{Frage 5}

Welcher der folgenden mit der Nahrung zugeführten Nährstoffe ist nicht am Methylgruppenstoffwechsel der Zelle beteiligt?
A Folate (synthetische Form: Folsäure)
B Methionin
C Vitamin $\mathrm{E}$
D Cholin
E Betain

\section{Frage 6}

Welche Aussage zur Ernährung trifft nicht zu?

A Die individuelle genetische Sequenz einer Zelle wird durch die Ernährung beeinflusst.

B Das Epigenom einer Zelle kann durch die Ernährung beeinflusst werden.

C Nutritive Faktoren können bei Schwangeren auch die Epigenetik der F2-Generation beeinflussen.

D Im Tiermodell wurde ein Zusammenhang zwischen der Folsäureversorgung während der Schwangerschaft und der Gewichtsentwicklung der Nachkommen beobachtet.

E Die Folsäureüberdosierung während der Schwangerschaft ist nach heutigem Kenntnisstand unbedenklich, da Folsäure wasserlöslich ist und über die Niere ausgeschieden wird. 


\section{CME-Fragen bei CME.thieme.de}

Fortsetzung ...

\section{Frage 7}

Welche Aussage zur epigenetischen Beeinflussung ist richtig?

A Epigenetische Einflüsse werden über Modifizierung der mitochondrialen DNA in den Eizellen an die Nachkommen weitergegeben.

B Eine epigenetische Beeinflussung der paternalen Spermien führt nicht zu Veränderungen in den Nachkommen.

C Das Genom von eineiigen Zwillingen unterscheidet sich mit zunehmendem Alter.

D Das Epigenom von eineiigen Zwillingen unterscheidet sich mit zunehmendem Alter.

E Das Epigenom von eineiigen Zwillingen unterscheidet sich bei der Geburt nicht.

\section{Frage 8}

Welche Aussage ist richtig?

A Das Genom einer Zelle verändert sich mit jeder Zelldifferenzierung.

B Das Epigenom einer Zelle verändert sich mit jeder Zelldifferenzierung.

C Äußere Faktoren beeinflussen immer nur das Epigenom der Nachfolgegeneration.

D Nach neuesten Erkenntnissen werden die Mendel'schen Gesetze durch die Epigenetik außer Kraft gesetzt.

E Eine methylgruppenreiche Diät erhöht die Anzahl der Histonmoleküle entlang der DNA.

\section{Frage 9}

Welche Aussage zur Genstilllegung trifft nicht zu?

A Das Epigenom kann den Phänotyp eines Lebewesens beeinflussen.

B Imprinting bezeichnet den Spezialfall der Genstilllegung, bei dem gezielt entweder das maternale oder das paternale Allel durch DNA-Methylierung abgeschaltet wird.

C Im weiblichen Embryo des Menschen wird immer das mütterliche der beiden X-Chromosomen stillgelegt.

D In der Zygote werden die Methylierungsmuster sowohl auf dem väterlichen als auch dem mütterlichen Allel gelöscht. Nur bei einigen wenigen Genen, die dem Imprinting unterliegen, bleibt die Methylierung erhalten.

E Auch nach der Reprogrammierung bleibt das Epigenom äußeren Einflüssen unterworfen.

\section{Frage 10}

Welche Aussage bzgl. RNA trifft nicht zu?

A Auf weit über $90 \%$ der DNA sind keine Gene lokalisiert, die für Proteine kodieren.

B Diese Abschnitte können den Code für sog. nicht kodierende RNA enthalten.

C MicroRNAs unterdrücken die Transkription einzelner Gene („silencing“).

D MicroRNAs übernehmen eine bedeutende Funktion als Regulatoren der Histonmodulation in den Zellen.

E Die RNA-Interferenz durch microRNA gehört neben der DNA-Methylierung und der Histonacetylierung zu den bisher bekannten epigenetischen Mechanismen. 